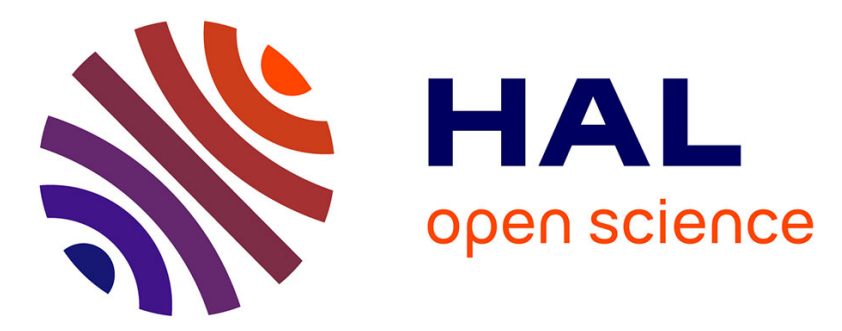

\title{
Bandgap Engineering from Cation Balance: the Case of Lanthanide Oxysulfide Nanoparticles
}

\author{
Clément Larquet, Anh-Minh Nguyen, Estelle Glais, Lorenzo Paulatto, \\ Capucine Sassoye, Mohamed Selmane, Pierre Lecante, Clement Maheu, \\ Christophe Geantet, Luis Cardenas, et al.
}

\section{To cite this version:}

Clément Larquet, Anh-Minh Nguyen, Estelle Glais, Lorenzo Paulatto, Capucine Sassoye, et al.. Bandgap Engineering from Cation Balance: the Case of Lanthanide Oxysulfide Nanoparticles. Chemistry of Materials, 2019, 10.1021/acs.chemmater.9b00450 . hal-02167240

\section{HAL Id: hal-02167240 https://hal.sorbonne-universite.fr/hal-02167240}

Submitted on 27 Jun 2019

HAL is a multi-disciplinary open access archive for the deposit and dissemination of scientific research documents, whether they are published or not. The documents may come from teaching and research institutions in France or abroad, or from public or private research centers.
L'archive ouverte pluridisciplinaire HAL, est destinée au dépôt et à la diffusion de documents scientifiques de niveau recherche, publiés ou non, émanant des établissements d'enseignement et de recherche français ou étrangers, des laboratoires publics ou privés. 


\section{Bandgap Engineering from Cation Balance: the Case of}

\section{Lanthanide Oxysulfide Nanoparticles}

Clément Larquet, ${ }^{1,2}$ Anh-Minh Nguyen, ${ }^{1}$ Estelle Glais, ${ }^{1,3}$ Lorenzo Paulatto, ${ }^{2}$ Capucine Sassoye, ${ }^{1}$ Mohamed Selmane, ${ }^{4}$ Pierre Lecante, ${ }^{5}$ Clément Maheu, ${ }^{6}$ Christophe Geantet, ${ }^{6}$ Luis Cardenas, ${ }^{6}$ Corinne Chanéac, ${ }^{1}$ Andrea Gauzzi, ${ }^{2}$ Clément Sanchez, ${ }^{1}$ Sophie Carenco ${ }^{1, *}$

${ }^{1}$ Sorbonne Université, CNRS UMR 7574, Collège de France, Laboratoire de Chimie de la Matière Condensée de Paris (LCMCP), 4 place Jussieu, 75252 Paris Cedex 05, France

${ }^{2}$ Institut de Minéralogie de Physique des Matériaux et de Cosmochimie (IMPMC), Sorbonne Université, CNRS UMR 7590, IRD UMR 206, MNHN, 4 place Jussieu 75252 Paris Cedex 05, France

${ }^{3}$ PSL Research University, IRCP, Chimie ParisTech, CNRS, 11 rue P. et M. Curie, 75231 Paris Cedex 05, France.

${ }^{4}$ Sorbonne Université, Institut des Matériaux de Paris Centre (IMPC), 75252 Paris Cedex 05, France

${ }^{5}$ CEMES-CNRS, 29 rue Jeanne Marvig, 31055 Toulouse Cedex 4, France

${ }^{6}$ Université de Lyon, Institut de Recherches sur la Catalyse et l'Environnement de Lyon IRCELYON - UMR 5256, CNRS-UCB Lyon 1, 2 avenue Albert Einstein 69626 Villeurbanne cedex, France.

\footnotetext{
* Corresponding author e-mail: sophie.carenco@ sorbonne-universite.fr
} 


\section{Abstract:}

Among the inorganic compounds, many oxides and sulfides are known to be semiconductors. At the crossroads of these two families, oxysulfide $\mathrm{M}_{x} \mathrm{O}_{y} \mathrm{~S}_{z}$ compounds were much less investigated because they are scarce in nature and complex to synthesize. Amongst them, lanthanide oxysulfide $\mathrm{Ln}_{2} \mathrm{O}_{2} \mathrm{~S}$ ( $\mathrm{Ln}=$ lanthanide) are indirect bandgap semiconductors, with wide gaps, except $\mathrm{Ce}_{2} \mathrm{O}_{2} \mathrm{~S}$.

$(\mathrm{Gd}, \mathrm{Ce})_{2} \mathrm{O}_{2} \mathrm{~S}$ anisotropic nanoparticles with hexagonal structure were obtained over the whole composition range and exhibit colors varying from white to brown with increasing $\mathrm{Ce}$ concentration. Bandgap engineering is thus possible, from $4.7 \mathrm{eV}$ for $\mathrm{Gd}_{2} \mathrm{O}_{2} \mathrm{~S}$, to $2.1 \mathrm{eV}$ for $\mathrm{Gd}_{0.6} \mathrm{Ce}_{1.4} \mathrm{O}_{2} \mathrm{~S}$, while the structure is preserved with a slight lattice expansion. Surprisingly, due to the limited thickness of the lamellar nanoparticles, the bandgap of the nanoparticles is direct as validated by density functional theory on slabs. The fine control of the bandgap over a wide range, solely triggered by the cation ratio, is rarely described in the literature and highly promising for further development of this class of compounds. We propose a multiregime mechanism to rationalize the bandgap engineering over the whole composition range. This should inspire the design of other bimetallic nanoscaled compounds, in particular in the field of visible light photocatalysis. 


\section{Context and objectives}

The crystallographic structure of lanthanide and actinide oxysulfide $\mathrm{RE}_{2} \mathrm{O}_{2} \mathrm{~S}$ (RE: rare earth) was solved for the first time during the 1940 's. ${ }^{1,2}$ From these pioneering works, numerous studies were published on the preparation of these phases and their optical properties. In particular, doped $\mathrm{Ln}_{2} \mathrm{O}_{2} \mathrm{~S}$ ( $\mathrm{Ln}=\mathrm{La}, \mathrm{Gd}, \mathrm{Y}$ ) turned out to be excellent phosphors with good efficiencies for scintillators, ${ }^{3,4}$ upconversion materials ${ }^{5-8}$ and bioimaging capabilities. ${ }^{9-11}$ These crystalline phases are stable in air.

With the development of nanotechnologies during the past 20 years, rare-earth based materials, and especially $\mathrm{Ln}_{2} \mathrm{O}_{2} \mathrm{~S}$ oxysulfide nanoparticles, emerged due to a growing interest for nanophosphors with good chemical and thermal stability, lower toxicity and better luminescence quantum efficiency than oxides. Among others, Ding and coworkers developed a versatile colloidal synthesis in organic solvents for $\mathrm{Ln}_{2} \mathrm{O}_{2} \mathrm{~S}$ nanoparticles $(\mathrm{Ln}=\mathrm{Y}, \mathrm{La}, \mathrm{Pr}$, $\mathrm{Nd}, \mathrm{Sm}-\mathrm{Tb}) .{ }^{12}$ The properties of doped $\mathrm{Ln}_{2} \mathrm{O}_{2} \mathrm{~S}$ oxysulfides were widely explored, but only a few studies focused on the properties of these without doping.

$\mathrm{Ce}_{2} \mathrm{O}_{2} \mathrm{~S}$ is a peculiar case in the $\mathrm{Ln}_{2} \mathrm{O}_{2} \mathrm{~S}$ series because $\mathrm{Ce}$ (III can easily oxidize into Ce ${ }^{\mathrm{IV}}$. This unique reactivity, related to the [Xe] $5 d^{0} 4 f^{1}$ electronic configuration of $\mathrm{Ce}^{\mathrm{III}}$, led to the description of mixed-valence structure of cerium oxysulfides, namely $\mathrm{Ce}_{2} \mathrm{O}_{2.5} \mathrm{~S},{ }^{13,14}$ $\mathrm{Ce}_{4} \mathrm{O}_{4} \mathrm{~S}_{3},{ }^{15}$ and $\mathrm{Ce}_{6} \mathrm{O}_{6} \mathrm{~S}_{4}{ }^{16}$ In air and at room temperature, bulk $\mathrm{Ce}_{2} \mathrm{O}_{2} \mathrm{~S}$ slowly oxidizes. ${ }^{17,18}$ We showed in a previous work that $\mathrm{Ce}_{2} \mathrm{O}_{2} \mathrm{~S}$ nanoparticles can be obtained, provided that synthesis and storage are performed under inert atmosphere. $15 \mathrm{~nm}$ wide and $2 \mathrm{~nm}$ thick nanoplates were formed by colloidal synthesis in organic solvent. Because of their high specific surface, brief exposition to air or water swiftly oxidize both cerium and sulfur, triggering the degradation of the nanoparticles. ${ }^{19}$ Bimetallic lanthanide oxysulfides $(\mathrm{Gd}, \mathrm{Ce})_{2} \mathrm{O}_{2} \mathrm{~S}$ nanoparticles were also synthesized and their stability in air was found to decrease when the Ce:Gd ratio increase: up to $40 \%$ cerium $v s$. gadolinium, the nanoparticles 
were structurally stable, although significant surface oxidation was observed on both sulfur and cerium. ${ }^{19}$

Beyond its lack of stability in air, $\mathrm{Ce}_{2} \mathrm{O}_{2} \mathrm{~S}$ is also peculiar because of its electronic and optical properties. Unlike the other lanthanide compounds, $\mathrm{Ce}_{2} \mathrm{O}_{2} \mathrm{~S}$ is not whitish but deep brown. ${ }^{13,17}$ This absorption of the visible light suggests that $\mathrm{Ce}_{2} \mathrm{O}_{2} \mathrm{~S}$ is a semiconductor whose bandgap is much lower than the others $\left(<2.0 \mathrm{eV}\right.$ for $\mathrm{Ce}_{2} \mathrm{O}_{2} \mathrm{~S},>3.0 \mathrm{eV}$ for the other lanthanide oxysulfides).

In this work, the optical and electronic properties of the bimetallic $\mathrm{Gd}_{2(1-y)} \mathrm{Ce}_{2 y} \mathrm{O}_{2} \mathrm{~S}$ nanoparticles are discussed. First, UV-diffuse reflectance spectra demonstrate the presence of two regimes in the $\mathrm{Gd}_{2(1-y)} \mathrm{Ce}_{2 y} \mathrm{O}_{2} \mathrm{~S}$ series: (i) a "doping" regime for low $y$ values for which two distinct absorption phenomena are observed and (ii) a "solid solution" regime for $y \geq 5 \%$ with a large absorption band which shifts with cerium concentration. In the latter case, the nanoparticles bandgap is progressively evolving with their composition. Second, an accurate description of the nanocrystal obtained with a typical colloidal synthesis is presented and accounts for the lack of sulfur in the final compound. Then, DFT calculations on $\mathrm{Gd}_{2} \mathrm{O}_{2} \mathrm{~S}$ and $\mathrm{Ce}_{2} \mathrm{O}_{2} \mathrm{~S}$ show that the reduced thickness of the nanoparticles explain their direct bandgap (while the bulk compound has an indirect bandgap). ${ }^{20}$ This reconciles the colors of the powders with the bandgaps extracted from absorption spectra in UV-visible range. To the best of our knowledge, this work presents the first example of wide bandgap variation that is easily controlled from the cations ratio in the solid solution of an inorganic phase. It occurs without significant structure evolution. 


\section{Results and discussion}

\subsection{Optical properties - Ln/Ce substitution and bandgap evolution}

\section{Absorption of $\mathrm{Gd}_{2(1-y)} \mathrm{Ce}_{2 y} \mathrm{O}_{2} \mathrm{~S}$ nanoparticles}

In a previous work, we reported the synthesis of $\mathrm{Ce}_{2} \mathrm{O}_{2} \mathrm{~S}$ nanoparticles that are unstable when exposed to air. However, we showed that it is possible to obtain a large range of cerium-containing $\mathrm{Gd}_{2(1-y)} \mathrm{Ce}_{2 y} \mathrm{O}_{2} \mathrm{~S}$ nanoparticles that are stable in air. ${ }^{19} \mathrm{We}$ also showed that the ligands around $\mathrm{Gd}_{2} \mathrm{O}_{2} \mathrm{~S}$ nanoparticles are oleates in bridging and chelating coordination modes. ${ }^{21}$ Here, cerium loading is defined as $y=n_{\mathrm{Ce}} /\left(n_{\mathrm{Ce}}+n_{\mathrm{Gd}}\right)$ where $n$ refers to the initial metallic precursor quantity in mol. The $\mathrm{Gd} / \mathrm{Ce}$ ratios of the precursors introduced at the beginning of the reaction and measured by energy dispersive X-ray spectroscopy (EDX) on the isolated product were consistent (Table S1 and Figure S0), meaning that the ratio in the final powder is similar to the introduced one. The nanoparticles were slightly larger when they were richer in cerium (Table S2) but they presented a similar thickness of three lattice units (Figure S3).

More $\mathrm{Ce}^{\mathrm{III}}$ in the structure in place of $\mathrm{Gd}^{\mathrm{III}}$ strongly affects light absorption of the $\mathrm{Gd}_{2(1-y)} \mathrm{Ce}_{2 y} \mathrm{O}_{2} \mathrm{~S}$ nanoparticles powders, from white $(y=0 \%)$ to brown $(y=70-90 \%)$. The Kubelka-Munk function $\left(F(R)=(1-R)^{2} / 2 R\right.$ where $R$ is the reflectance, see Figure $\left.\mathrm{S} 1\right)$ is linearly related to the extinction coefficient of the material and thus to its absorption properties. ${ }^{22}$ The $F(R)$ spectra of the $\mathrm{Gd}_{2(1-y)} \mathrm{Ce}_{2 y} \mathrm{O}_{2} \mathrm{~S}$ nanoparticles are plotted in Figure 1A. The shoulders at ca $300 \mathrm{~nm}$ are due to organic ligands. Note that the range of wavelengths where light is absorbed increases with Ce fraction. In agreement with the change of colors observed in the powders (Figure $\mathrm{S} 1$ ), $\mathrm{Gd}_{2} \mathrm{O}_{2} \mathrm{~S}$ absorbs only in the UV region while Ce-rich nanoparticles absorb a large fraction of the visible light (brown powders).

Although this evolution is gradual, two regimes can be distinguished (Figure 1). In the doping regime $(0 \%<y \leq 2 \%)$, two inflexion points are observed with a smooth absorption increase 
before $500 \mathrm{~nm}$ and a sharp increase around $270 \mathrm{~nm}$, close to the absorption step of $\mathrm{Gd}_{2} \mathrm{O}_{2} \mathrm{~S}$. In the solid solution regime $(y \geq 5 \%)$, only the smooth increase of absorption is observed and this feature shifts towards higher wavelengths.
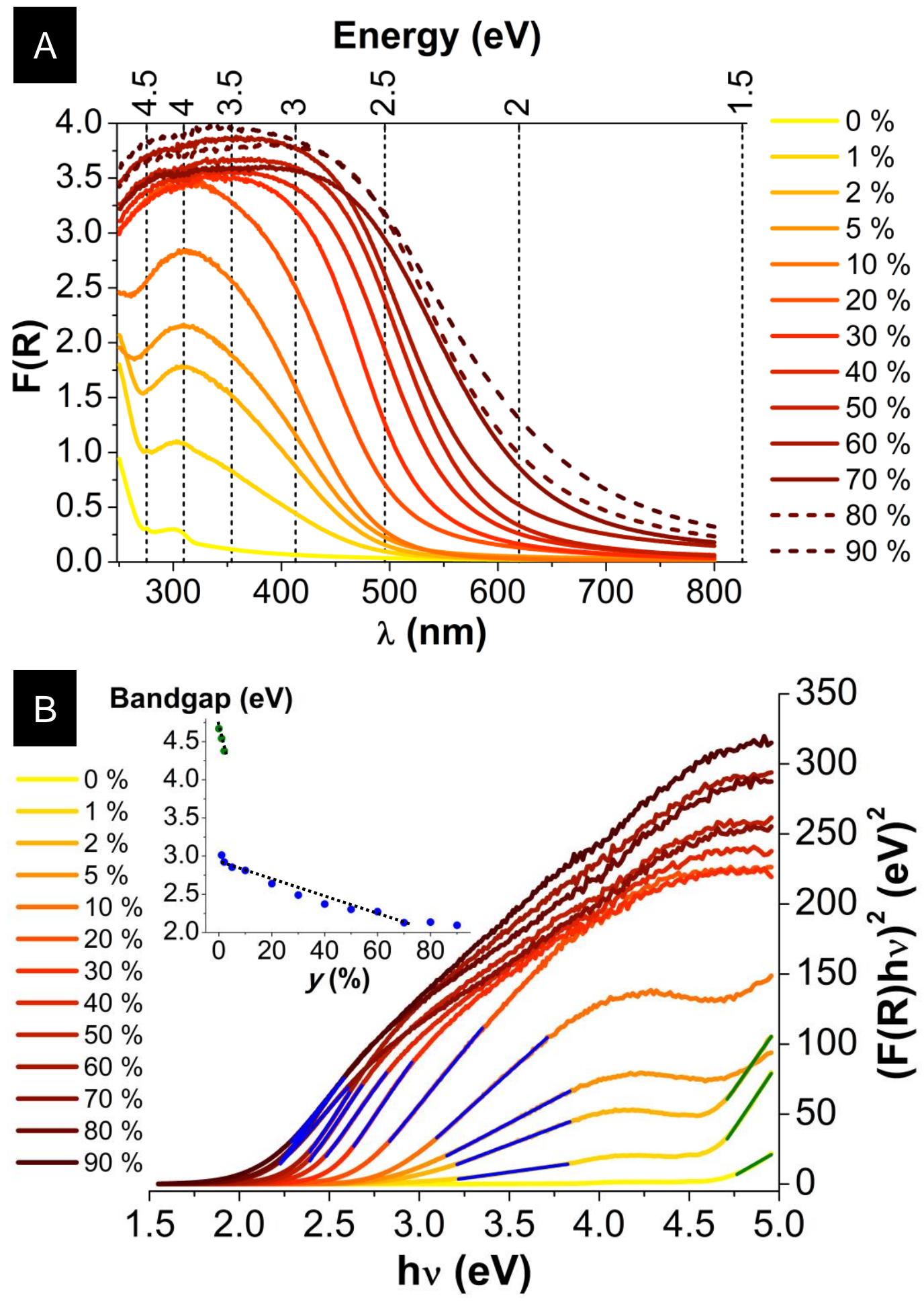
Figure 1: Optical properties of $(\mathrm{Gd}, \mathrm{Ce})_{2} \mathrm{O}_{2} \mathrm{~S}$ nanoparticles. (A) $F(R)$ spectra obtained from UV-visible diffuse reflectance of $\mathrm{Gd}_{2(1-y)} \mathrm{Ce}_{2 y} \mathrm{O}_{2} \mathrm{~S}$ nanoparticles for $y$ in the $0-90 \%$ range. Samples $y=80 \%$ and $y=90 \%$ are indicated by dashed lines because these samples are unstable in air. (B) Evolution of the $(F(R) h v)^{2} v s$. $h v$ curves as a function of composition. Dark green and blue lines are a linear extrapolation of the data. Inset: dependence of the optical bandgap extracted from the above curves on Ce-composition, $y$, for the whole series of $\mathrm{Gd}_{2(1-y)} \mathrm{Ce}_{2 y} \mathrm{O}_{2} \mathrm{~S}$ nanoparticles. The dashed black lines are guides to the eye.

\section{Bandgap of $\mathrm{Gd}_{2(1-y)} \mathrm{Ce}_{2 y} \mathrm{O}_{2} \mathrm{~S}$ nanoparticles}

Thanks to the work by Kubelka et al. ${ }^{22}$ and later analyzed by Tauc et al., ${ }^{23}$ it is possible to extract the value of the bandgap from the reflectance spectra using the $F(R)$ function (Figure 1B). This model is parameterized by a power $n$ which depends on the type of bandgap. Then the extrapolation of the linear portion of the $(F(R) h v)^{n} v s . h v$ curves enables to estimate the bandgap.

In a first report, Mikami et al. suggested that the bandgap of $\operatorname{Ln}_{2} \mathrm{O}_{2} \mathrm{~S}$ compounds is indirect. ${ }^{20,24}$ In this case, $n=1 / 2$. However, in recent reports on $\operatorname{Ln}_{2} \mathrm{O}_{2} \mathrm{~S}$ compounds, it was argued that the bandgap is direct, which corresponds to $n=2 \cdot{ }^{25,26}$ Here, the absorption of the powders are in agreement with the latter picture, as the assumption $n=1 / 2$ yielded unphysical values of $1.2-4.1 \mathrm{eV}$ (color mismatch) (see Figure S8). Thus, hereafter we assume a picture of direct bandgap for the $\mathrm{Gd}_{2(1-y)} \mathrm{Ce}_{2 y} \mathrm{O}_{2} \mathrm{~S}$ nanoparticles.

The analysis of the $F(R)$ spectra of $\mathrm{Gd}_{2(1-y)} \mathrm{Ce}_{2 y} \mathrm{O}_{2} \mathrm{~S}$ nanoparticles is presented on Figure 1B. For $y \geq 5 \%$ (solid solution regime), the linear zone on the $(F(R) h v)^{2}$ curve gives a bandgap below $3 \mathrm{eV}$. For the two compounds in the range $0 \%<y<5 \%$ (doping regime), two values were extracted from the curves: (i) one related to cerium insertion (low energy region $2.9-3.1 \mathrm{eV}$ ) and (ii) the other close to the bandgap of $\mathrm{Gd}_{2} \mathrm{O}_{2} \mathrm{~S}$ nanoparticles (high energy 
region $4.3-4.7 \mathrm{eV}$ ). For these two compounds, the aforementioned does not provide a unique value. However, the strong effect of cerium on the optical properties is evident from our data. Figure 1B inset shows the bandgaps extracted from the absorption spectra. The dark black line in the bottom indicates a linear trend for $y>2 \%$ (solid solution regime), although the reliability of the measurements obtained for $y=80 \%$ and $y=90 \%$ is questionable because of the limited stability of Ce-rich nanoparticles in air. ${ }^{19}$

The shift of bandgap between $\mathrm{Gd}_{2} \mathrm{O}_{2} \mathrm{~S}$ and $\mathrm{Gd}_{0.6} \mathrm{Ce}_{1.4} \mathrm{O}_{2} \mathrm{~S}(y=70 \%)$ is remarkably large $(2.6 \mathrm{eV})$, considering that the crystal structure is preserved. As shown in a previous work, the only structural change between the two samples consists in a $1.5 \%$ increase of lattice parameter $a$ as expected from Vegard's law. ${ }^{19}$

In the solid solution regime, the bandgap of the nanocrystals is tunable between $3.0 \mathrm{eV}$ and $2.1 \mathrm{eV}$ by adjusting the nanoparticles composition. To some extent, in the high energy region, the bandgap is also tunable in the doping regime between $4.7 \mathrm{eV}$ and $4.4 \mathrm{eV}$ (inset of Figure $1 \mathrm{~B}$, green points). In the doping regime, a relatively large energy gap separates the two energy regions $(>1 \mathrm{eV})$ corresponding to the two distinct absorption phenomena. We will see in the final sections that replacing $\mathrm{Gd}^{\mathrm{III}}$ by $\mathrm{Ce}^{\mathrm{III}}$ disrupts the electronic properties of $\mathrm{Gd}_{2} \mathrm{O}_{2} \mathrm{~S}$ nanoparticles in a large extent. We can suspect that the mixed valence of cerium ${ }^{19}$ can be at least partially responsible for the strong absorption in the visible range but so far, we have no experimental evidence to support this hypothesis.

\section{Comparison with other class of compounds}

Bandgap engineering enabling large changes of absorption spectra has been discussed for many materials. In general, these changes typically require significant structural changes. In composite semi-conductors, the gap energy variation is related to the interatomic distance. That is why bandgap shifts can be observed as a consequence of anionic or cationic substitution. The more the structure is modified (variation of the interatomic distances), the 
higher the expected shift. For example, the anionic substitution was investigated in hybrid lead-halide perovskites, extensively studied for their promising properties for solar cells applications. $^{27}$ The substitution of bromine by iodine in $(\mathrm{CHA})_{2} \mathrm{PbBr}_{4(1-x)} \mathrm{I}_{4 x}$ $(\mathrm{CHA}=$ cyclohexylammonium $)$ is accompanied by a bandgap decrease of $\sim 0.7 \mathrm{eV}$ between $(\mathrm{CHA})_{2} \mathrm{PbBr}_{4}$ and $(\mathrm{CHA})_{2} \mathrm{PbI}_{4}$ but with significant structural modifications. ${ }^{28}$ Solid solutions of $\mathrm{CdS}_{x} \mathrm{Se}_{1-x}$ are also known to exhibit large absorption shifts. ${ }^{29}$ Copper zinc tin sulfide $(\mathrm{CZST})^{30}$ and Copper indium gallium selenide (CIGS) ${ }^{31}$ thin films also exhibit a bandgap that is related to the cations stoichiometry and may vary in a broad range. Similar effect was observed on gallium indium oxide nanoparticles. ${ }^{32}$ In the case of oxysulfides, $\mathrm{Sm}_{2} \mathrm{Ti}_{2} \mathrm{O}_{7}$ and $\mathrm{Sm}_{2} \mathrm{Ti}_{2} \mathrm{O}_{5} \mathrm{~S}_{2}$ show a bandgap variation of $\Delta \mathrm{E}_{\mathrm{g}} \approx 1.6 \mathrm{eV}$ but no solid solution can be formed. ${ }^{33}$ The substitution of two cations also significantly changes the bandgap: $3.8 \mathrm{eV}$ for $\mathrm{ZnS}, 2.5 \mathrm{eV}$ for $\mathrm{CdS}$ and $2.1 \mathrm{eV}$ for $\alpha-\mathrm{HgS}^{34}$ In addition to strong variations of lattice parameter in isostructural solid solutions, the substitution of zinc by cadmium in $\mathrm{Zn}_{1-x} \mathrm{Cd}_{x} \mathrm{~S}$ drives a cubic blende $\mathrm{ZnS}$ to hexagonal CdS structural transition. ${ }^{35}$

In conclusion, the present system is rare because, within well-defined and small nanoplates, the cationic substitution is responsible for an important absorption shift with neither structural nor morphological modifications. In view of this promising result, we investigated whether Ce-substitution constitutes an exception or other substitutions would give similar results.

\section{Comparison with Pr and Eu cation balance}

We have chosen $\mathrm{Ce}_{2} \mathrm{O}_{2} \mathrm{~S}$ among all $\mathrm{Ln}_{2} \mathrm{O}_{2} \mathrm{~S}$ compounds because it is the only low bandgap semiconductor. The insertion of other lanthanides is expected to have less effect on the absorption. Also, the question arises whether the insertion of Ce in other $\operatorname{Ln}_{2} \mathrm{O}_{2} \mathrm{~S}$ compounds may lead to absorption shifts similar to those observed in $\mathrm{Gd}_{2(1-y)} \mathrm{Ce}_{2 y} \mathrm{O}_{2} \mathrm{~S}$ nanoparticles.

Other bimetallic nanoparticles were synthesized to investigate this effect. We selected Pr and $\mathrm{Eu}$, the former because of its cation size $(1.20 \AA)$ close to Ce $(1.21 \AA)$, the latter because of its 
two oxidation states (here, $+\mathrm{II}$ and $+\mathrm{III})$. Using $\mathrm{Ce}(\mathrm{acac})_{3} \cdot x \mathrm{H}_{2} \mathrm{O}, \operatorname{Pr}(\mathrm{acac})_{3} \cdot x \mathrm{H}_{2} \mathrm{O}$, $\mathrm{Eu}(\text { acetate })_{3} \cdot x \mathrm{H}_{2} \mathrm{O}$ and $\mathrm{Gd}(\mathrm{acac})_{3} \cdot x \mathrm{H}_{2} \mathrm{O}$ as lanthanide precursors, nanoparticles of $\operatorname{Pr}_{2} \mathrm{O}_{2} \mathrm{~S}$ (light green powder), $\mathrm{Eu}_{2} \mathrm{O}_{2} \mathrm{~S}$ (white powder), $\mathrm{Gd}_{1.8} \mathrm{Pr}_{0.2} \mathrm{O}_{2} \mathrm{~S}$ (white powder), $\mathrm{Gd}_{1.8} \mathrm{Eu}_{0.2} \mathrm{O}_{2} \mathrm{~S}$ (white powder), $\operatorname{Pr}_{1.8} \mathrm{Ce}_{0.2} \mathrm{O}_{2} \mathrm{~S}$ (orange powder), and $\mathrm{Eu}_{1.8} \mathrm{Ce}_{0.2} \mathrm{O}_{2} \mathrm{~S}$ (yellow powder) were obtained. The $F(R)$ spectra of these bimetallic nanoparticles are presented on Figure 2.

For $\mathrm{Gd}_{1.8} \mathrm{Ln}_{0.2} \mathrm{O}_{2} \mathrm{~S}$ compounds $(\mathrm{Ln}=\mathrm{Ce}, \mathrm{Pr}, \mathrm{Eu})$, the most significant effect on the absorption is obtained with cerium (Figure 2A). For $\mathrm{Gd}_{1.8} \operatorname{Pr}_{0.2} \mathrm{O}_{2} \mathrm{~S}$, two absorption edges are observed at $280 \mathrm{~nm}$ close to $\mathrm{Gd}_{2} \mathrm{O}_{2} \mathrm{~S}$ edge and $320 \mathrm{~nm}$ closer to the absorption edge of $\operatorname{Pr}_{2} \mathrm{O}_{2} \mathrm{~S}$ (around $350 \mathrm{~nm}$, Figure 2B and C). In the case of europium, the edge is shifted to lower wavelengths (below $250 \mathrm{~nm}$ ) and a broad peak on the curve grows around $340 \mathrm{~nm}$ (Figure 2B). 
A Sample color and bandgap (eV) of $\mathrm{A}_{1.8} \mathrm{~B}_{0.2} \mathrm{O}_{2} \mathrm{~S}$ nanoparticles

\begin{tabular}{l|cccc}
\hline Ad & Ce & Pr & Eu & Gd \\
\hline Eu & 2.8 & 4.3 & {$[a]$} & 4.7 \\
& 2.5 & 3.2 & 3.2 & \\
$\mathbf{P r}$ & 2.6 & 3.6 & & \\
$\mathbf{C e}$ & 1.8 & &
\end{tabular}

[a] No measure possible in this absorption range
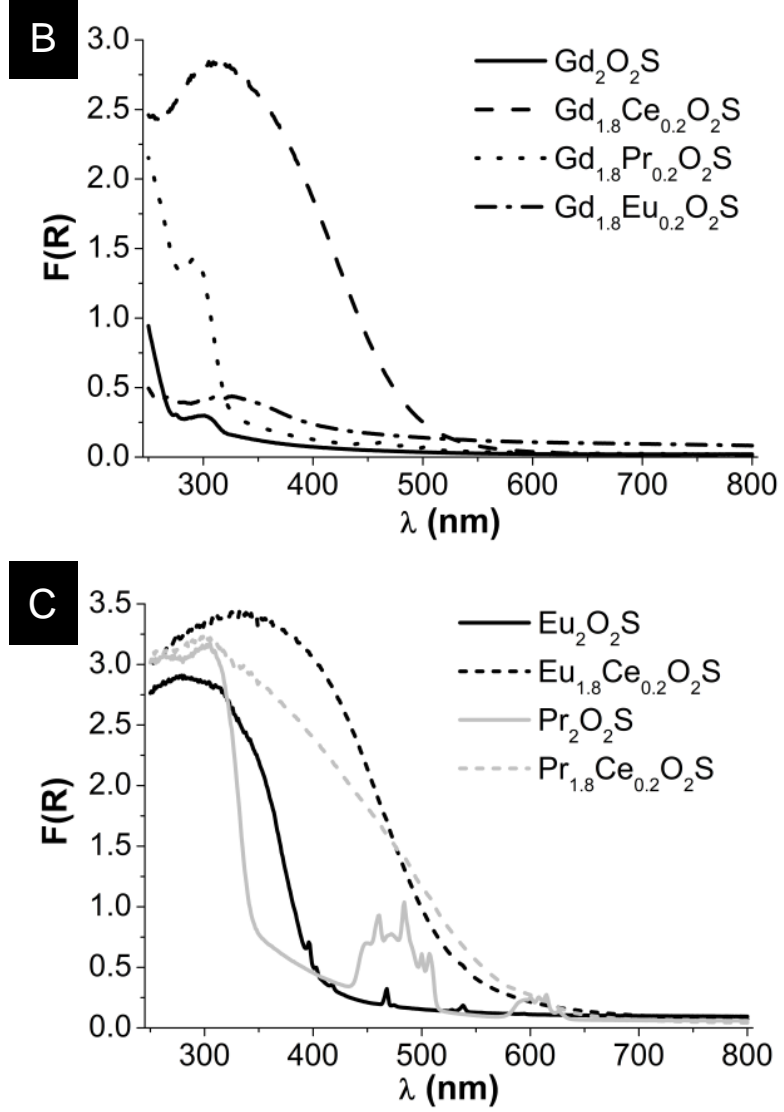

Figure 2: Optical properties of $\left(\operatorname{Ln}^{1}, \mathrm{Ln}^{2}\right)_{2} \mathrm{O}_{2} \mathrm{~S}$ nanoparticles. (A) Sample colors and bandgap values estimated using the model proposed by Tauc et al. for $\mathrm{A}_{1.8} \mathrm{~B}_{0.2} \mathrm{O}_{2} \mathrm{~S}$ nanoparticles $\left(n_{B} /\left(n_{A}+n_{B}\right)=10 \%\right) .{ }^{23} F(R)$ spectra for (B) gadolinium-based bimetallic $\operatorname{Gd}_{1.8} \operatorname{Ln}_{0.2} \mathrm{O}_{2} \mathrm{~S}$ oxysulfides, with $\mathrm{Ln}=\mathrm{Ce}$, $\mathrm{Pr}$ and $\mathrm{Eu}$; (C) $\mathrm{Eu}_{2} \mathrm{O}_{2} \mathrm{~S}, \mathrm{Eu}_{1.8} \mathrm{Ce}_{0.2} \mathrm{O}_{2} \mathrm{~S}, \mathrm{Pr}_{2} \mathrm{O}_{2} \mathrm{~S}$ and $\mathrm{Pr}_{1.8} \mathrm{Ce}_{0.2} \mathrm{O}_{2} \mathrm{~S}$. The $\mathrm{Eu}_{1.8} \mathrm{Pr}_{0.2} \mathrm{O}_{2} \mathrm{~S}$ spectrum is presented on Figure $\mathrm{S} 2$. 
Inserting cerium in $\operatorname{Pr}_{2} \mathrm{O}_{2} \mathrm{~S}$ and $\mathrm{Eu}_{2} \mathrm{O}_{2} \mathrm{~S}$ leads to similar effects on light absorption than $\mathrm{Gd}_{2} \mathrm{O}_{2} \mathrm{~S}\left(\mathrm{Ln}_{1.8} \mathrm{Ce}_{0.2} \mathrm{O}_{2} \mathrm{~S}\right.$ compounds, Figure $\left.2 \mathrm{~B}\right)$, even if the bandgap shift caused by $\mathrm{Ce}^{\mathrm{III}}$ in gadolinium oxysulfide remains by far the largest. The nanoparticles absorb higher wavelengths as the bandgap decreases. Moreover, the absorption peaks specific to transitions between $4 f$ energy levels of the monometallic compounds are no longer present in the bimetallic compounds whose absorption curves are smooth.

These results demonstrate that the effect of cerium on the bandgap is not specific to gadolinium compounds. Instead, the incorporation of cerium allows tuning the bandgap of at least two other $\mathrm{Ln}_{2} \mathrm{O}_{2} \mathrm{~S}$ compounds $(\mathrm{Ln}=\mathrm{Pr}$ or $\mathrm{Eu})$.

Cerium appeared to be unique among the lanthanide investigated. To explain the bandgap nature and its huge sensitivity of the optical properties to the Ce concentration, we underwent an in-depth structural and modeling study.

\section{2. $\mathrm{Gd}_{2(1-y)} \mathrm{Ce}_{2 y} \mathrm{O}_{2} \mathrm{~S}$ nanoplates: a sulfur-deficient structure}

\section{Nanoparticles morphology}

The $\mathrm{Gd}_{2(1-y)} \mathrm{Ce}_{2 y} \mathrm{O}_{2} \mathrm{~S}$ nanoparticles crystallize in the $P-3 m l$ crystal group. The structure is hexagonal and alternates layers of $\left[\mathrm{Ln}_{2} \mathrm{O}_{2}\right]^{2+}$ and $[\mathrm{S}]^{2-} \cdot{ }^{36}$ In this structure, Gd and Ce form a solid solution. ${ }^{19}$ In the present case, as in other authors works, ${ }^{11,37}$ the formed nanoparticles possess a hexagonal anisotropic shape with exacerbated $\{001\}$ facets.

Transmission Electron Microscopy (TEM) micrographs show nanoparticles either observed lying on this $\{001\}$ facet (Figure 3A, Figure S3), or exposing their $\{100\}$ facet (Figure 3B, Figure S3). In both cases, the nanoparticles are packed in fairly regular arrangements that are a consequence of specific interactions between the surface ligands. $\mathrm{Gd}_{2(1-y)} \mathrm{Ce}_{2 y} \mathrm{O}_{2} \mathrm{~S}$ nanoparticles are 10 to $15 \mathrm{~nm}$ wide when $y>5 \%$ and 7 to $10 \mathrm{~nm}$ wide otherwise. This is in agreement with the calculated Scherrer's crystal domains obtained from the XRD patterns (see Figure S4 and Table S2), meaning that the nanoparticles are single-crystals. 


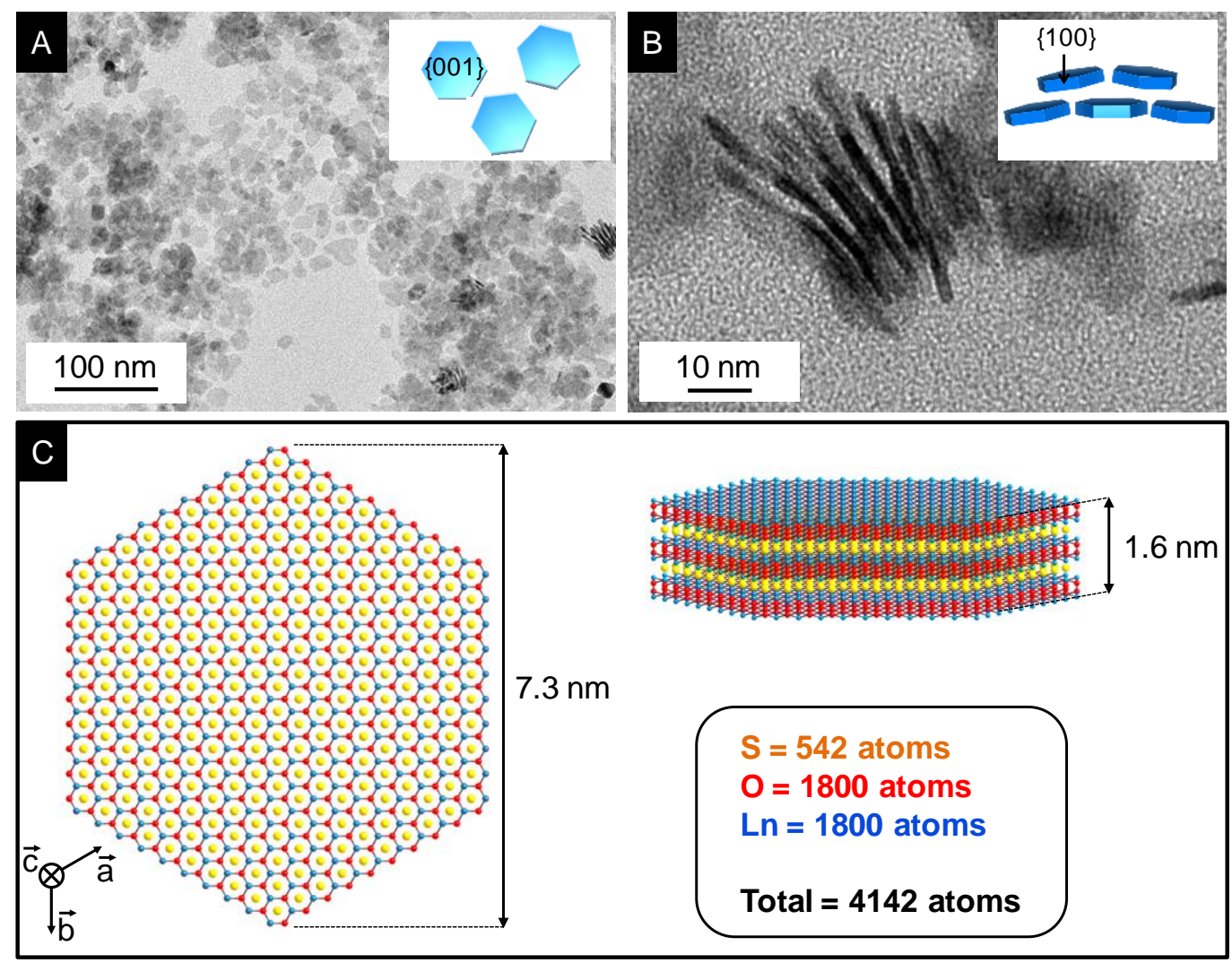

Figure 3: Morphology of the nanoparticles. TEM micrographs of frontal (A) and lateral (B) views of $\mathrm{Gd}_{1.25} \mathrm{Ce}_{0.75} \mathrm{O}_{2} \mathrm{~S}$ nanoparticles. (C) Simplified representation of the inorganic structure of the $\mathrm{Ln}_{2} \mathrm{O}_{2} \mathrm{~S}$ nanoparticles in which the outer layers are stabilized by oleate ligands (omitted on the scheme). The number of atoms depicted is in agreement with the nanoparticles average size from TEM micrographs (Figure S3).

\section{Sulfur-defective nanoparticles}

First, energy dispersive X-ray spectroscopy (EDS) performed on $\mathrm{Gd}_{2(1-y)} \mathrm{Ce}_{2 y} \mathrm{O}_{2} \mathrm{~S}$ nanoparticles showed a significant lack of sulfur (Table S1), as reported by us and other groups performing a similar synthesis. ${ }^{11,37}$ Only 40 to $50 \%(\mathrm{~S}: \mathrm{Gd}=0.2-0.25)$ of the expected sulfur is found in the powders of $\mathrm{Gd}_{2(1-y)} \mathrm{Ce}_{2 y} \mathrm{O}_{2} \mathrm{~S}$ nanocrystals. However, we discussed in a previous study the surface oxidation of sulfur into sulfite and sulfate groups for this series of bimetallic Gd-Ce nanoparticles when they are exposed to air. We can thus imagine an extreme case in which sulfur is only exposed through the $\{100\}$ facets of the 
particles and completely absent from the $\{001\}$ facets. In this particular case, the nanoparticle terminates with $\left[\mathrm{Gd}_{2} \mathrm{O}_{2}\right]^{2+}$ layers on $\{001\}$ facets and surface gadolinium cations on these layers can be coordinated by oleate ligands. The theoretical S:Gd ratio is not anymore 0.50 , as in the bulk compound, but only 0.37 . Removing all surface sulfur (not only on $\{001\}$ facets but also on $\{100\}$ facets $)$ leads to a lower $\mathrm{S}$ : Gd ratio of $0.30\left(\mathrm{Gd}_{2} \mathrm{O}_{2} \mathrm{~S}_{0.6}\right.$ nanoparticles, Table S3). The corresponding nanoparticle is represented on Figure 3C.

To balance the charge caused by the lack of sulfur, the presence of organic ligands at the surface of the nanoparticles is necessary. These ligands come from the colloidal synthesis, which requires oleylamine and oleic acid. The presence of oleate moieties in the powder was confirmed by Fourier-transform infrared spectroscopy (FTIR, Figure S5), which showed the typical bands of carboxylate $\mathrm{C}=\mathrm{O}$ double bonds at $1500 \mathrm{~cm}^{-1}$ and $1383 \mathrm{~cm}^{-1}$. Thermogravimetric analysis coupled with mass spectrometry (TGA-MS) indicated around $30 \mathrm{wt} \%$ of organic compounds in synthesized $\mathrm{Gd}_{2} \mathrm{O}_{2} \mathrm{~S}$ and confirmed the absence of oleylamine (data not shown). We thus propose that only oleate groups cap the $\left[\operatorname{Ln}_{2} \mathrm{O}_{2}\right]^{2+}$ layers on each side of the particles, id est on both the $\{001\}$ and the $\{100\}$ facets.

Although these models are only ideal cases, they all concord to support that the nanoplates are sulfur-defective and are terminated by $\left[\mathrm{Ln}_{2} \mathrm{O}_{2}\right]^{2+}$ layers capped with oleates. In order to confirm this, we performed a structural analysis sensitive to defects: pair distribution function analysis. This technique was also used to discuss the localization of sodium cations, which are generally believed to substitute $\mathrm{Gd}^{\mathrm{III}}$ cations in $\mathrm{Ln}_{2} \mathrm{O}_{2} \mathrm{~S}$ structures. ${ }^{37,38}$

\section{Pair distribution function analysis}

X-ray diffraction pattern of $\mathrm{Gd}_{2} \mathrm{O}_{2} \mathrm{~S}$ nanoparticles was measured on a large angular range with a low-background home-made sample-holder. The pair distribution function (PDF) was calculated from total X-Ray scattering as described in the experimental section. It was compared with simulated patterns. 


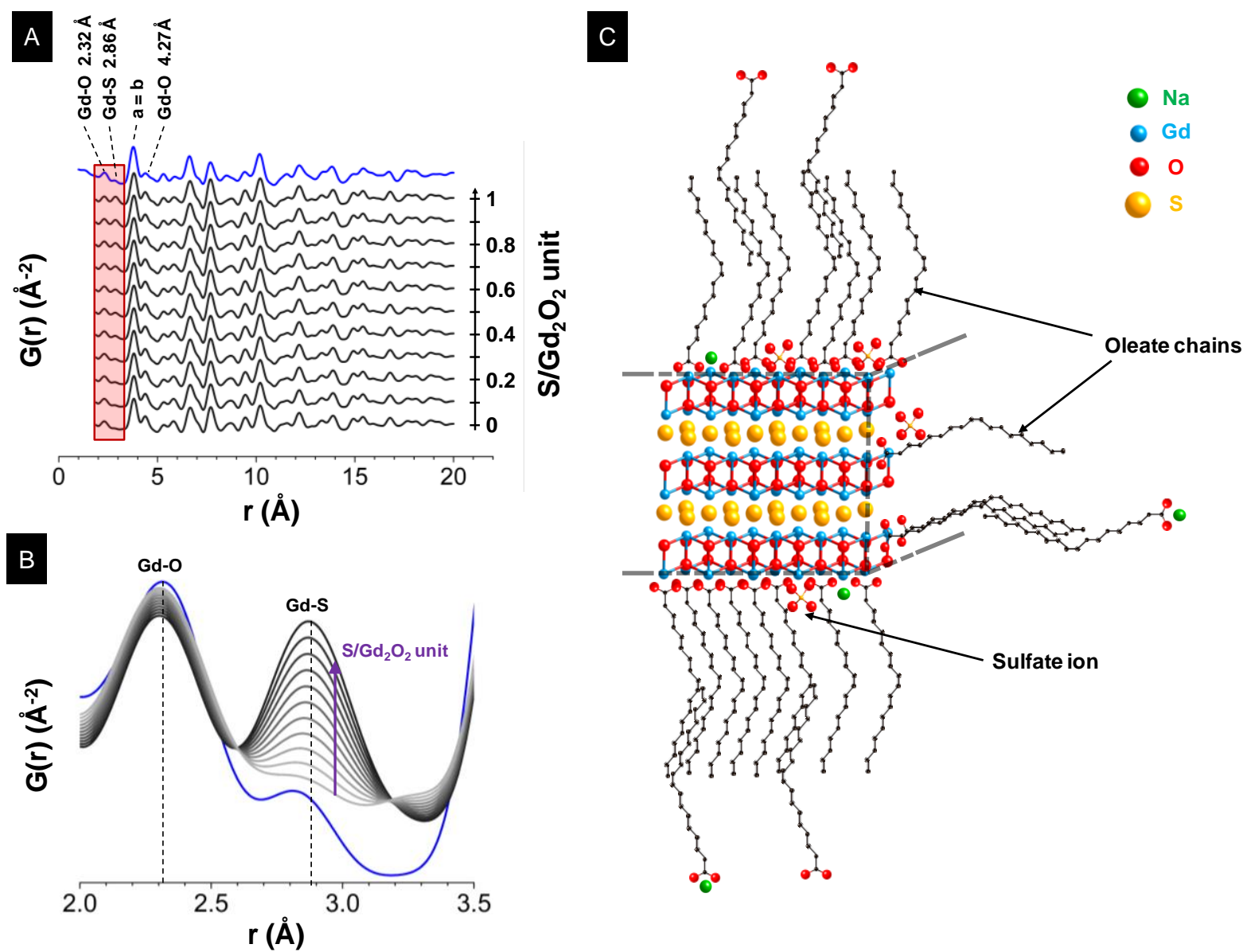

Figure 4: Structure of the nanoparticles. (A) Pair distribution function $G(r)$ obtained from X-ray scattering patterns of $\mathrm{Gd}_{2} \mathrm{O}_{2} \mathrm{~S}$ nanoparticles $\left(G(r)_{\text {exp }}\right.$, blue) and calculated from $\mathrm{Gd}_{2} \mathrm{O}_{2} \mathrm{~S}$ bulk structure described in the JCPDS file 08-6593 imposing different sulfur occupancies

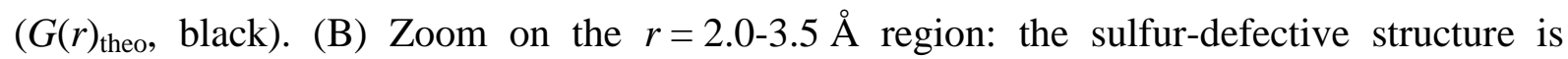
evidenced by the ratio of the intensities of Gd-O and Gd-S peaks. (C) Refined schematic view of the $\mathrm{Ln}_{2} \mathrm{O}_{2} \mathrm{~S}$ nanoparticles.

Real space calculated and experimental PDF are compared here without any further structure refinement, given the complexity of correctly evaluating PDF from finite anisotropic nanoparticles. Moreover, the presence of oleate ligands and oxidized sulfur ions $\left(\mathrm{SO}_{3}{ }^{2-}\right.$, $\mathrm{SO}_{4}{ }^{2-}$ ), surrounding each particle is not taken into account here. Evolutions in peak positions related to the atomic pairs are discussed here and their relative intensities $v s$. nanoparticles composition are analyzed. 
As seen on Figure 4, the calculated and experimental PDF are mostly similar (the relative intensity of the second peak at $r=2.86 \AA$ will be discussed in the following paragraph), confirming the validity of the published structure $\mathrm{Gd}_{2} \mathrm{O}_{2} \mathrm{~S}$ as a model for the nanoparticles. The positions of the experimental PDF peaks match with the positions of the calculated ones, confirming that atomic distances within the particle are similar to these of the bulk structure. This shows that the $\mathrm{Na}^{+}$and $\mathrm{SO}_{4}{ }^{2-}$ ions detected by EDX, XPS and FTIR ${ }^{19}$ are not inserted inside the core cells. Despite their close ionic radius $\left(\mathrm{Gd}^{\mathrm{III}}(\mathrm{VII})=1,14 \AA\right.$, $\mathrm{Ce}^{\mathrm{III}}(\mathrm{VII})=1,21 \AA$, $\left.\mathrm{Na}^{\mathrm{I}}(\mathrm{VII})=1,26 \AA\right),{ }^{39}$ sodium ions are not in the final crystalline structure.

The $2.86 \AA$ peak, representing the Gd-S pair, appears experimentally with a smaller intensity than the calculated one for $\mathrm{Gd}_{2} \mathrm{O}_{2} \mathrm{~S}$. To account for this difference, a series of models with decreasing $\mathrm{S}^{-\mathrm{II}}$ occupancy was simulated (Figure $4 \mathrm{~B}$ ). The $\mathrm{S} /\left(\mathrm{Gd}_{2} \mathrm{O}_{2}\right)$ ratio mostly affects the relative intensity of the Gd-S peak, with best match around half $\mathrm{S}$ atoms from ideal structure. This value is in the same range than those expected from EDS measurements on several aggregates of particles.

One could expect that such low statistical occupancy for $\mathrm{S}^{-\mathrm{II}}\left(0.5\right.$ occupancy for each $\left.\mathrm{S}^{-\mathrm{II}}\right)$ would lead to clear cell parameter contraction. This is clearly not the case here: whenever allowed to refine, cell parameters variations were balanced and negligible. As discussed previously, the anisotropic shape and size of the particle already lead to a sulfur deficient stoichiometry of $\mathrm{Gd}_{2} \mathrm{O}_{2} \mathrm{~S}_{0.6}$. The experimental $0.5 \mathrm{~S}: \mathrm{Gd}$ ratio would then correspond to an $85 \%$ occupancy of the available sulfur position in the particle. Again, the absence of cell contraction means that the main core of the particle keeps a $\mathrm{Gd}_{2} \mathrm{O}_{2} \mathrm{~S}$ structure. The structural equivalence of the anisotropic $\mathrm{Gd}_{2} \mathrm{O}_{2} \mathrm{~S}_{\sim 0.5}$ nanoparticles with $\mathrm{Ln}_{2} \mathrm{O}_{2} \mathrm{~S}$ cells allows to seek from density functional theory (DFT) calculations an explanation of the bandgap and the optical properties of $(\mathrm{Gd}, \mathrm{Ce})_{2} \mathrm{O}_{2} \mathrm{~S}$ nanoparticles. 
Moreover, the PDF analysis tends to demonstrate a $\mathrm{Ln}_{2} \mathrm{O}_{2} \mathrm{~S}$ crystalline structure without any defect. It is in accordance with the previous results obtained with our accurate estimations of the crystalline domain sizes of $\mathrm{Gd}_{2(1-y)} \mathrm{Ce}_{2 y} \mathrm{O}_{2} \mathrm{~S}$ nanoparticles for which we chose to use the Scherrer's formula that supposes perfectly ordered crystals (Table S2).

\subsection{Investigation of the bandgap nature using density functional calculations}

DFT calculations were performed in order to understand the unexpected direct nature of the bandgap. After a series of works, Mikami et al. concluded in 2006 from DFT that the bandgaps of $\mathrm{Ln}_{2} \mathrm{O}_{2} \mathrm{~S}$ (and $\mathrm{Ce}_{2} \mathrm{O}_{2} \mathrm{~S}$ in particular) were indirect. ${ }^{20,24}$ However, we suggest that the calculations accuracy would be significantly improved by including in valence the $4 f$ electrons of the lanthanide metals that are of great importance for their electronic properties. Furthermore, to be as close as possible to the nanoplates represented on Figure 4C (S:Gd ratio), we also performed DFT on a specific "slab" geometry. Here, capping agents that stabilize the surfaces of the nanoplate were not considered because we supposed that only the crystal (core of the nanoplate) was responsible for the optical properties. Yet, the nature of the ligands may slightly influence the band structure.

The calculations were only focused on three layers of the studied $\mathrm{Gd}_{2} \mathrm{O}_{2} \mathrm{~S}$ or $\mathrm{Ce}_{2} \mathrm{O}_{2} \mathrm{~S}$ oxysulfide, that can be stabilized by hydrogen atoms instead of sulfur atoms when needed (sulfur-free $\{001\}$ surfaces). This model structure mimics the absence of sulfur in the external layers (replaced by oleate ligands in reality) and avoids dangling electronic states that make the system metallic (see in SI the details on the DFT+U calculations). 


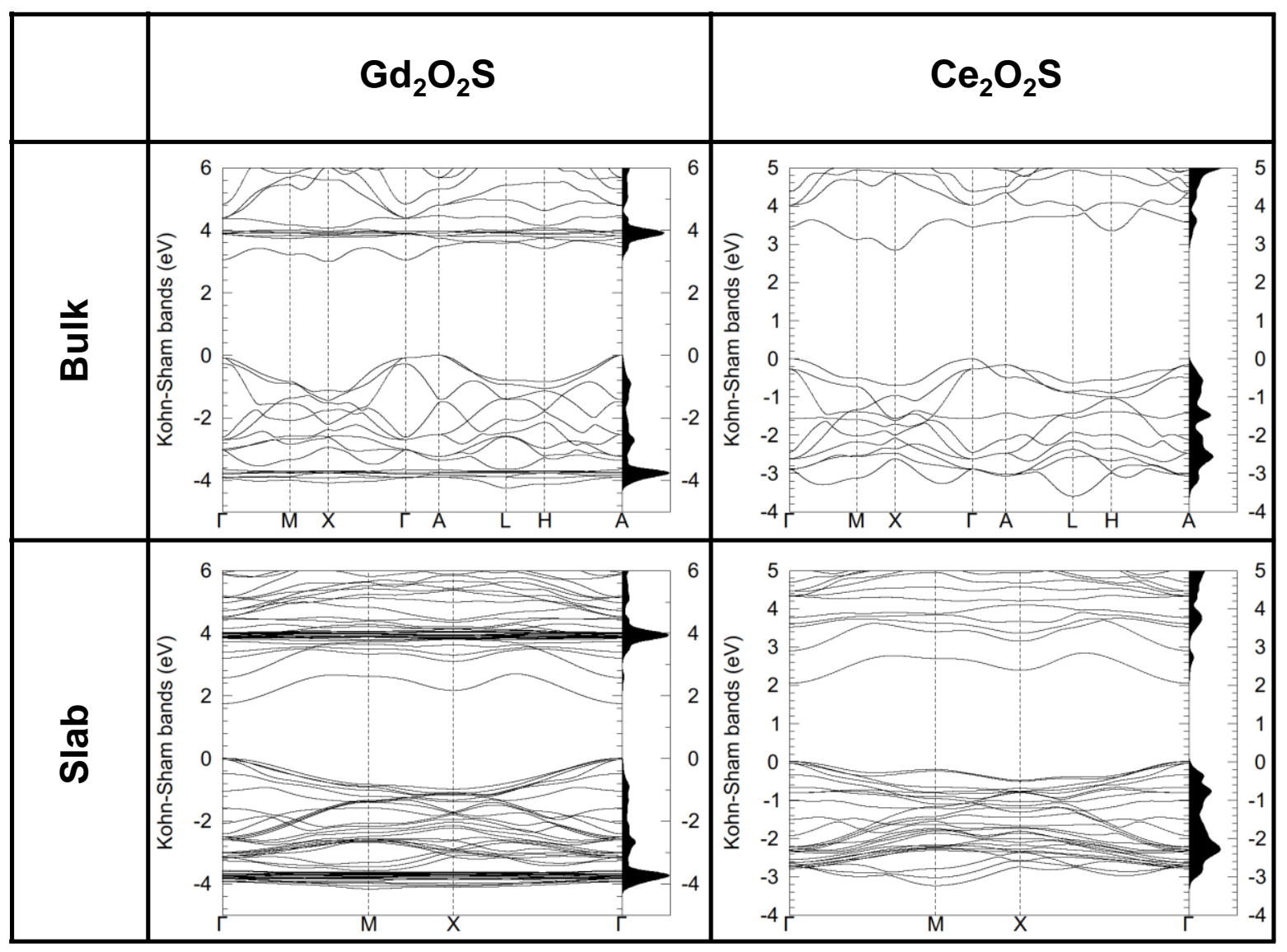

Figure 5: Band structures of $\mathrm{Ln}_{2} \mathrm{O}_{2} \mathrm{~S}(\mathrm{Ln}=\mathrm{Gd}, \mathrm{Ce}$ ) in the bulk (top) or for the slab geometry (bottom).

The band structures of the bulk phases of $\mathrm{Gd}_{2} \mathrm{O}_{2} \mathrm{~S}$ and $\mathrm{Ce}_{2} \mathrm{O}_{2} \mathrm{~S}$ are presented on Figure 5 . Interestingly, we found that the bandgap is indirect even if the $4 f$ electrons of the lanthanides are treated as valence electrons. Nevertheless, there are significant differences with the work of Mikami et al. on $\mathrm{Ce}_{2} \mathrm{O}_{2} \mathrm{~S}$ and the bandgap transition is different. ${ }^{20}$

More importantly, the slab geometry has a great influence on the band structure for both $\mathrm{Gd}_{2} \mathrm{O}_{2} \mathrm{~S}$ and $\mathrm{Ce}_{2} \mathrm{O}_{2} \mathrm{~S}$ (Figure 5, bottom) as it reduces the symmetry of the system. Moreover, the bandgap of the slab is direct in both cases. We can thus conclude that the nanoplate morphology (anisotropy, low dimensions) explains the variation of electronic properties. It also reconciles our optical measurements and the DFT calculations on a system composed by 
$\mathrm{Ln}_{2} \mathrm{O}_{2} \mathrm{~S}$ nanoparticles. Further analysis using photon-in photon-out spectroscopy such as Resonant inelastic X-ray scattering (RIXS) may further strengthen this argument.

\subsection{Bandgap nature of $(\mathrm{Gd}, \mathrm{Ce})_{2} \mathrm{O}_{2} \mathrm{~S}$ nanoparticles in relation with the substitution ratio}

The cationic substitution between Gd and Ce drastically modifies the electronic properties of the oxysulfide nanoparticles. We performed additional spectroscopic analyses to determine the electronic changes caused by $\mathrm{Gd} / \mathrm{Ce}$ substitution.

Figure 6A displays the photoluminescence (PL) excitation and emission spectra of $\mathrm{Gd}_{2(1-y)} \mathrm{Ce}_{2 y} \mathrm{O}_{2} \mathrm{~S}$ nanoparticles. Cerium d-f transition results in a characteristic multiplet spectrum. ${ }^{40}$ Remarkably, the $\mathrm{Ce}^{\mathrm{III}}$ emission persists even for $y=20 \%$, indicating a well dispersed luminescent cation inside the structure, preventing quenching phenomena and thus confirming the structural hypothesis of a true solid solution based on XRD. Moreover, there is no significant change, neither in the absorption nor in the emission spectral positions between the samples. In particular, the excitation threshold wavelength $\left(\lambda_{\mathrm{thr}}=205 \mathrm{~nm}\right)$ and the $5 d \rightarrow 4 f$ deexcitation wavelengths are similar regardless of $y$ value. Hence, excitation of $\mathrm{Ce}^{\mathrm{III}}$ cations in $\mathrm{Gd}_{2(1-y)} \mathrm{Ce}_{2 y} \mathrm{O}_{2} \mathrm{~S}$ nanoparticles requires a constant energy, which is higher than the bandgap. Moreover, the band shapes indicate that the $\mathrm{Ce}^{\mathrm{III}} 5 d$ emitting levels are the same for $y=1-$ $20 \%$. However, it is hard to distinguish the transitions $5 d \rightarrow{ }^{2} \mathrm{~F}_{5 / 2}$ (Ce $\mathrm{Ce}^{\mathrm{III}}$ ground state) from $5 d \rightarrow{ }^{2} \mathrm{~F}_{7 / 2}$ (spin-orbit excited term), so we arbitrarily chose the first case to illustrate our system in Figure 6C. ${ }^{41,42}$

In addition, ultraviolet photoelectron spectroscopy (UPS) was performed on the samples with $y=0$ and $30 \%$, in order to see how the Ce substitution influence the position of the valence band. To conduct UPS on powders, the dropping method reported lately is used. ${ }^{43}$ The latter requires a solvent which may induce an interfacial dipole between the powder and the ITO substrate and so, a global shift of the spectra. As detailed on Figure S6, we aligned the samples at their Fermi levels. It allows measuring relative position of the valence maximum. 
Between $y=0 \%$ and $y=30 \%$, a significant upward shift of $0.5 \mathrm{eV}$ of the valence band is observed (Figure 6B). This is consistent with the reduced bandgap of the material. The bandgap is however decreased by a larger value $(2.2 \mathrm{eV})$ compared with these of $\mathrm{Gd}_{2} \mathrm{O}_{2} \mathrm{~S}$. We thus propose that the bandgap engineering caused by $\mathrm{Gd} / \mathrm{Ce}$ substitution is majorly due to the variation of the conduction band.

A careful background subtraction allows commenting the experimental density of states determined with UPS. Figure 6B inset evidenced that the valence band states are modified by $\mathrm{Gd} / \mathrm{Ce}$ substitution. For $y=30 \%$, the intensities of the states between 8 and $10 \mathrm{eV}$ increased while the intensities of the states between 3 and $5 \mathrm{eV}$ decreased. Those states are assigned to the Kohn-Sham bands between -1.5 and $-3.0 \mathrm{eV}$ (relatively to the valence band maximum) plotted on Figure 5 and reproduced in the inset. On Figure 6B, Ce states responsible for the valence band shift are observed between 1.5 and $3.5 \mathrm{eV}$ (black arrow). Accordingly, the band structure of $\mathrm{GdCeO}_{2} \mathrm{~S}$ phase $(y=50 \%$ ) confirms the increased density of these states (Figure S7). 

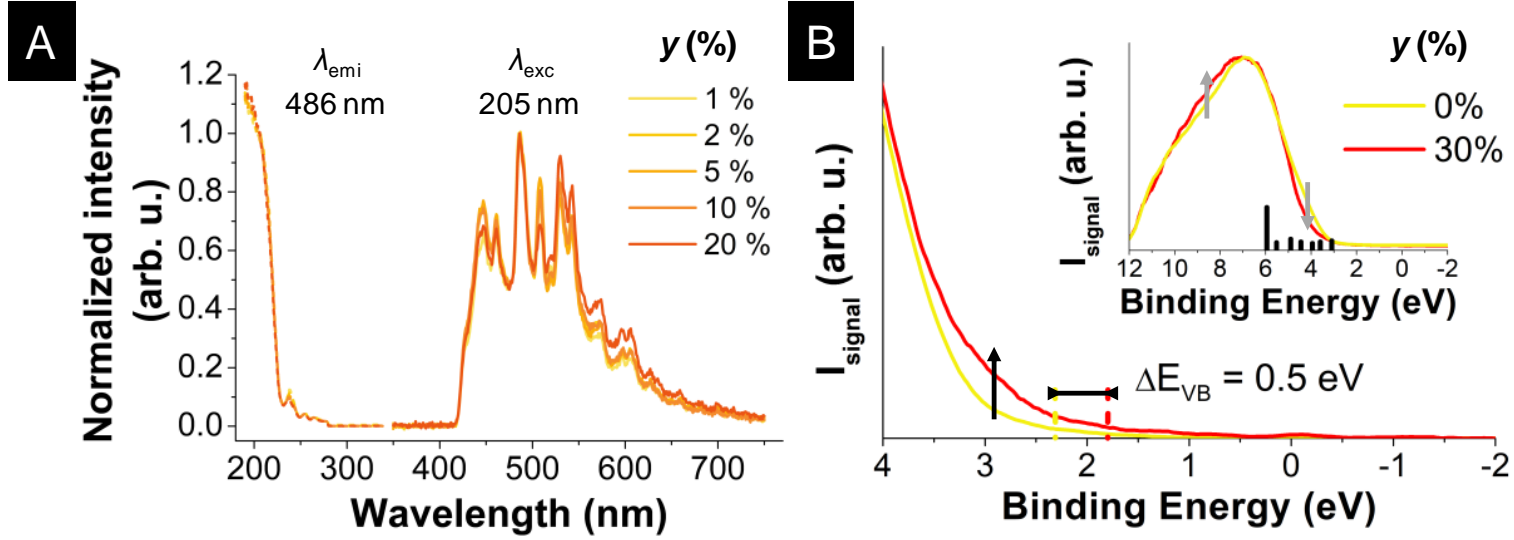

\section{C}

$\mathrm{Gd}_{2} \mathrm{O}_{2} \mathrm{~S}$

$y=0 \%$

$$
\begin{gathered}
\mathrm{Gd}_{1.98} \mathrm{Ce}_{0.02} \mathrm{O}_{2} \mathrm{~S} \\
y=1 \%
\end{gathered}
$$
$\mathrm{Gd}_{1.4} \mathrm{Ce}_{0.6} \mathrm{O}_{2} \mathrm{~S}$
$y=30 \%$
$\mathrm{Gd}_{0.6} \mathrm{Ce}_{1.4} \mathrm{O}_{2} \mathrm{~S}$
$y=70 \%$

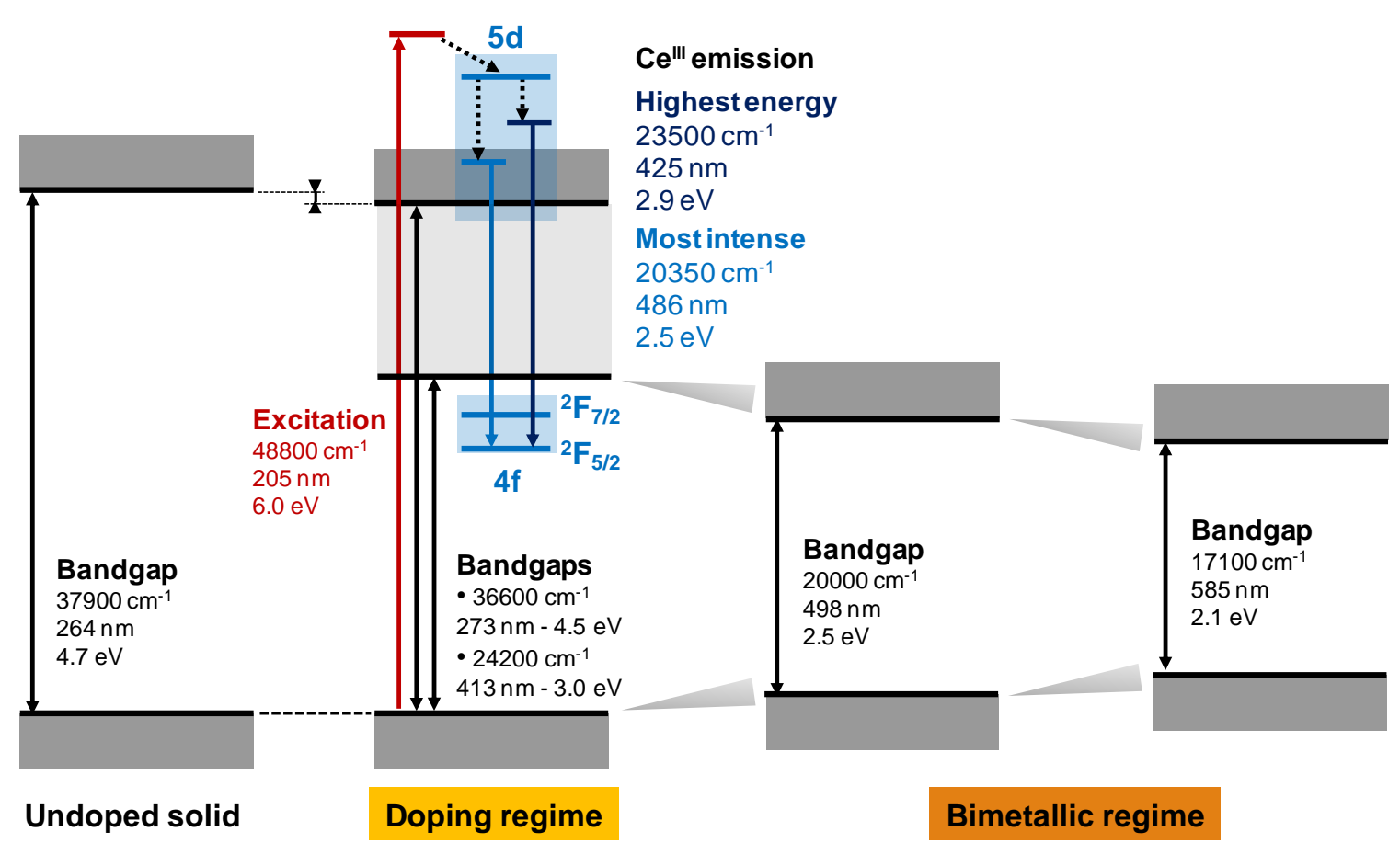

Figure 6: Bandgap engineering of the nanoparticles. (A) Photoluminescence excitation and emission spectra of $(\mathrm{Gd}, \mathrm{Ce})_{2} \mathrm{O}_{2} \mathrm{~S}$ nanoparticles respectively collected at $\lambda=486 \mathrm{~nm}$ and obtained with an excitation wavelength of $\lambda=205 \mathrm{~nm}$. The excitation spectra were normalized at $\lambda_{\mathrm{thr}}=205 \mathrm{~nm}$ and the emission spectra at $\lambda=486 \mathrm{~nm}$ (most intense emission). (B) Helium I ultraviolet photoemission spectra of $\mathrm{Gd}_{2(1-y)} \mathrm{Ce}_{2 y} \mathrm{O}_{2} \mathrm{~S}$ samples (with $y=0$ and $30 \%$ ). Background was subtracted ( $\mathrm{I}_{\text {signal }}=\mathrm{I}_{\mathrm{exp}}-\mathrm{I}_{\text {background }}$ ) and resulting spectra were normalized. Position of the valence band were determined from the $[-2.0 ; 4.0] \mathrm{eV}$ region displayed in the main spectra. Inset: UP spectra plotted in the $[-2.0-12.0] \mathrm{eV}$ region. 
$\mathrm{Gd}_{2} \mathrm{O}_{2} \mathrm{~S}$ band structure of the Figure 5 is plotted (bar chart) for comparison. (C) Evolution of the electronic properties of $\mathrm{Gd}_{2(1-y)} \mathrm{Ce}_{2 y} \mathrm{O}_{2} \mathrm{~S}$ nanoparticles vs. $y$.

Altogether, we describe the $\mathrm{Gd}_{2(1-y)} \mathrm{Ce}_{2 y} \mathrm{O}_{2} \mathrm{~S}$ nanoparticles as a multi-regime system (Figure 6C). $\mathrm{Gd}_{2} \mathrm{O}_{2} \mathrm{~S}$ nanoparticles exhibit a wide gap semiconductor behavior. With low fractions of cerium (in the "doping regime", $y \leq 10 \%$ ), the behavior is dual: cerium plays the role of (i) a classical doping ion (constant PL properties) with a small deviation from the high bandgap of $\mathrm{Gd}_{2} \mathrm{O}_{2} \mathrm{~S}$ and (ii) a nucleus of $\mathrm{Ce}_{2} \mathrm{O}_{2} \mathrm{~S}$ with its own absorption properties (low bandgap). The latter is the origin of the absorption properties for higher cerium concentrations ("bimetallic regime", $y>10 \%$ ) for which the electronic properties of the nanoparticles correspond to a solid solution $(\mathrm{Gd}, \mathrm{Ce})_{2} \mathrm{O}_{2} \mathrm{~S}$.

\section{Conclusion}

$(\mathrm{Gd}, \mathrm{Ce})_{2} \mathrm{O}_{2} \mathrm{~S}$ nanoparticles exhibit colors from white to brown over the whole composition range. Bandgap engineering is thus possible through cation exchange and values varying from $4.7 \mathrm{eV}$ in $\mathrm{Gd}_{2} \mathrm{O}_{2} \mathrm{~S}$ to $2.1 \mathrm{eV}$ in $\mathrm{Gd}_{0.6} \mathrm{Ce}_{1.4} \mathrm{O}_{2} \mathrm{~S}$ can be obtained without major structural modifications. Surprisingly, the bandgap of the nanoparticles is direct, as validated by density functional theory. This is a result of the limited thickness of the nanocrystals. The influence of the nanoplates width is yet to be explored. Bandgap engineering on $(\mathrm{Gd}, \mathrm{Ce})_{2} \mathrm{O}_{2} \mathrm{~S}$ nanoparticles may suggest applications in solar cells. The fine control of bandgap over a wide range, solely triggered by the cation ratio, is rare in the field of bandgap engineering, especially when considering nanoparticles. The simple idea of using suitable chemical substitutions producing minor structural changes should inspire the design of other bimetallic nanoscaled compounds, which may be promising especially in the field of visible light photocatalysis. 


\section{Experimental section}

\section{Synthesis of $\mathrm{Gd}_{2(1-y)} \mathrm{Ce}_{2 y} \mathrm{O}_{2} \mathrm{~S}$ nanoparticles}

Bimetallic oxysulfides were prepared via a solvothermal reaction including a mixture of organic solvents and metallic complexes. Oleylamine (OM; technical grade, $70 \%)$, oleic acid $(\mathrm{OA}$; technical grade, $90 \%)$, sulfur $\left(\mathrm{S}_{8} ; \geq 99.5 \%\right)$ and sodium oleate (Na(oleate); $\left.\geq 99 \%\right)$ were purchased from Sigma-Aldrich. 1-Octadecene (ODE; technical grade, $90 \%$ ) was purchased from Acros Organics. Gadolinium acetylacetonate hydrate $\left(\mathrm{Gd}(\mathrm{acac})_{3} \cdot x \mathrm{H}_{2} \mathrm{O}\right.$; $99.9 \%)$ and cerium acetylacetonate hydrate $\left(\mathrm{Ce}(\mathrm{acac})_{3} \cdot x \mathrm{H}_{2} \mathrm{O} ; 99.9 \%\right)$ were purchased from Strem Chemicals. All products were used as received without further purification.

In a typical synthesis of $\mathrm{GdCeO}_{2} \mathrm{~S}, \mathrm{Gd}(\mathrm{acac})_{3} \cdot x \mathrm{H}_{2} \mathrm{O} \quad(0.25 \mathrm{mmol}), \mathrm{Ce}(\mathrm{acac})_{3} \cdot x \mathrm{H}_{2} \mathrm{O}$ (0.25 mmol), $\mathrm{S}_{8}(0.032 \mathrm{mmol}), \mathrm{Na}$ (oleate) $(0.50 \mathrm{mmol}), \mathrm{OM}(17 \mathrm{mmol}), \mathrm{OA}(2.5 \mathrm{mmol})$ and ODE $(32.5 \mathrm{mmol})$ were placed in a $100 \mathrm{~mL}$ three-neck flask at room temperature. The brown solution was heated to $120{ }^{\circ} \mathrm{C}$ under vacuum for $20 \mathrm{~min}$ to remove water and other impurities with low boiling points. The mixture was then heated to $310{ }^{\circ} \mathrm{C}$ and stirred at this temperature for 30 min under purified $\mathrm{N}_{2}$. The transparent solution gradually became turbid starting from $280{ }^{\circ} \mathrm{C}$. Then the mixture was left to cool to room temperature under purified $\mathrm{N}_{2}$. The nanoparticles were isolated using ethanol and washed at least three times using a THF/ethanol (1/5 in volume) mixture to remove the remaining reagents and organic matter. 40 to $90 \mathrm{mg}$ of dried $\mathrm{Gd}_{2(1-y)} \mathrm{Ce}_{2 y} \mathrm{O}_{2} \mathrm{~S}$ particles was thus obtained depending on the initial cerium loading.

It should be noted that a significant decrease in the reaction yield (measured after several washings of the nanoparticles in air) is observed with increasing cerium concentration in the nanoparticles: starting from $0.5 \mathrm{mmol}$ of lanthanide precursor, a yield of around $100 \% \mathrm{vs}$. Gd (95 mg of powder) was obtained for $y=0 \%\left(\mathrm{Gd}_{2} \mathrm{O}_{2} \mathrm{~S}\right)$ while a yield of $48 \%$ (45 mg) was obtained for $y=70 \%\left(\mathrm{Gd}_{0.6} \mathrm{Ce}_{1.4} \mathrm{O}_{2} \mathrm{~S}\right)$.

$\operatorname{Pr}_{1.8} \mathrm{Ce}_{0.2} \mathrm{O}_{2} \mathrm{~S}$ and $\mathrm{Eu}_{1.8} \mathrm{Ce}_{0.2} \mathrm{O}_{2} \mathrm{~S}$ were synthesized with the same protocol and are stable in air. 


\section{X-ray Powder Diffraction (XRD)}

The different X-ray diffraction patterns of dry powders were measured on a Bruker D8 ADVANCE diffractometer using the $\mathrm{Cu}$ doublet $\mathrm{K} \alpha_{1} / \mathrm{K} \alpha_{2}$ radiation at $1.5406 \AA$. Typical diffractograms were collected with steps of $0.05^{\circ}$ and a scanning speed of 5 s/point with a 1D Lynxeye detector (Bruker). The backgrounds of the patterns were subtracted using the EVA software. When low noise Si monocristals sample holders were used, the angular position $2 \theta$ was corrected by adjusting the sample height (correction around 0.5 to $1 \mathrm{~mm}$ ).

\section{Transmission Electron Microscopy (TEM) and High Resolution TEM (HRTEM)}

A drop of a diluted solution of $\mathrm{Gd}_{2(1-y)} \mathrm{Ce}_{2 y} \mathrm{O}_{2} \mathrm{~S}$ dispersed in pure THF was allowed to dry on an amorphous carbon coated copper grid. TEM images were collected with a TWIN 120 (TECNAI SPIRIT) instrument at $120 \mathrm{kV}$ and with a Gatan Orius 1000 4k x 4k camera.

\section{Energy Dispersive X-ray Spectroscopy (EDS)}

A small amount of powder was deposited on carbon adhesive tape on a scanning electron microscope sample holder. EDX analyses were performed on a SEM HITACHI S-3400N instrument at $10 \mathrm{kV}$. Titanium was chosen as the reference and analyses were performed on at least three different zones on the sample.

\section{Fourier Transform Infrared Spectroscopy (FTIR)}

Infrared spectra were collected on a Spectrum 400 (PERKINELMER) spectrometer. The dry sample (1-3 mg) was deposited on an attenuated total reflectance (ATR) crystal. Transmittance was measured between $4000 \mathrm{~cm}^{-1}$ and $550 \mathrm{~cm}^{-1}$ with steps of $0.5 \mathrm{~cm}^{-1}$.

\section{UV diffuse reflectance}

Dry powders were loaded in the circular sample holder to make a uniform layer of solid. Powders were used, instead of solutions, first because the stability of the colloidal solutions is limited, second, in order to be able to perform other characterizations as well (XRD, UPS). The UV-visible diffuse reflectance spectra were measured using an integration sphere of a 
Cary-WinUV 5000 spectrophotometer (AGILENT) between $250 \mathrm{~nm}$ and $800 \mathrm{~nm}$ at $1 \mathrm{~nm} \cdot \mathrm{s}^{-1}$ and corrected with a sample of $\mathrm{BaSO}_{4}$ as reference. The $F(R)$ spectra were deducted using the formula $F(R)=\frac{(1-R)^{2}}{2 R}$, where $R$ is the reflectance. Depending on the bandgap (direct or indirect), linear zones could be extrapolated to 0 on the abscissa axis for the Tauc curve $(F(R) h v)^{n}=\mathrm{f}(h v)$ where $n=2$ for a direct bandgap and $n=1 / 2$ for an indirect bandgap.

\section{Pair distribution function analysis (PDF)}

The reduced atomic PDF, $G(r)$, gives, from a structural model, the probability of finding a pair of atoms at a distance of $r$ as follows:

$$
G(r)=4 \pi\left[\rho(r)-\rho_{0}\right]
$$

where $\rho(r)$ is the total atomic pair-density and $\rho_{0}$ is the average atomic number density. As defined, peaks in the $G(r)$ function point to specific distances separating a pair of atoms. $G(r)$ can also be extracted from an experimental XRD pattern. Indeed, $G(r)$ is the sine Fourier transform of the total reduced total scattering function $F(Q)=Q[S(Q)-1], S(Q)$ being the total scattering structure function:

$$
G(r)=\left(\frac{2}{\pi}\right) \cdot \int_{Q=0}^{\infty} Q \cdot[S(Q)-1] \cdot \sin (Q r) d Q
$$

where $Q$ is the magnitude of the scattering vector $(Q=4 \pi \sin (\theta) / \lambda), 2 \theta$ being the angle between the incoming and outgoing $\mathrm{X}$-ray, $\lambda$ is the X-ray wavelength, and $S(Q)$ is the total scattering structure function which is the corrected and normalized experimental intensity.

The experimental data were recorded from a standard laboratory D8 ADVANCE diffractometer (Bruker) equipped with a Mo anode (doublet $\mathrm{K}_{\alpha 1} / \mathrm{K}_{\alpha 2}$ radiation at $0.7093 \AA$ ), in the reflection mode, using a homemade sample holder designed to minimize its own signal. The large amount $(100 \mathrm{mg})$ of analyzed powder allows processing the signal with no further treatment such as sample holder background subtraction. Three patterns were recorded with a 1D Lynxeye detector (Bruker) with increasing step time (step size $=0.05^{\circ}, 2 \theta$ range; step 
time: $8-50^{\circ} ; 25 \mathrm{~s}, 50-90^{\circ} ; 50 \mathrm{~s}, 90-150^{\circ} ; 100 \mathrm{~s}$ ), converted in count per second and merged to obtain the full XRD pattern. The XRD data were then processed using the program PDFgetX3, from $Q=1.8$ to $15 \AA^{-1}$ to obtain $G(r)_{\text {exp. }}{ }^{44}$

On the other hand, the PDF data were modeled from the $\mathrm{Gd}_{2} \mathrm{O}_{2} \mathrm{~S}$ structure (PDF 04-008-6593) and compared with the experimental one using PDFGUI. ${ }^{45}$ Calculations in real space were performed for $r$ from 1 to $20 \AA$, way below the width of the hexagonal crystalline nanoplates, to reduce the effect of anisotropy. A mean size particle factor of $25 \AA$ was introduced for best attenuation in the high $r$ region. ${ }^{46,47}$

Real space calculated PDF are here compared without any further structure refinement (neither cell parameters nor atomic positions - thermal agitation were only adjusted to 0.01 ), given the complexity of correctly evaluating PDF from finite anisotropic nanoparticles.

\section{DFT calculations}

In the ab-initio simulation of rare-earth oxysulfides we have one main difficulty to tackle: how to treat the very localized, but not completely chemically inert, $f$ orbitals of the rare earth. The $4 f$ orbital contains 1 electron in the conventional isolated-atom structure of cerium, 7 electrons in gadolinium. The $4 f$ orbitals are localized inside a sphere of around $1 \AA$, centered on the atomic nucleus, but it is only partially filled and its binding energy is comparable with that of the chemically more active $5 d$ and $6 s$ orbitals. Even if these orbitals participate little in chemical bonds, their inclusion in the description of the valence structure is important to have an accurate band structure, especially in the lower energy valence bands.

The very strong self-interaction error, makes a simple DFT calculation impossible, to compensate the error, we have used the DFT+U technique. ${ }^{48,49}$ All calculations were done with the Quantum-ESPRESSO code ${ }^{50,51}$ using the PBE generalized gradient approximation. ${ }^{52}$ We used ultrasoft pseudopotentials with valence-bound $4 f$ orbitals from the pslibrary. ${ }^{53}$ These pseudopotentials trade an excellent transferability with an extremely high plane-wave cutoff 
of 200 Ry. Details on the method and results, including the relaxed geometry parameters, are in supplementary information.

\section{Photoluminescence}

Excitation and emission spectra were measured by Cary Eclipse Fluorescence Spectrophotometer. Powder samples were stuck on glass slide and excited at $205 \mathrm{~nm}$ for emission spectra. For excitation spectra the emission wavelength was fixed at $486 \mathrm{~nm}$. The excitation and emission spectra were respectively normalized by their intensity at $205 \mathrm{~nm}$ and $486 \mathrm{~nm}$.

\section{Ultraviolet Photoelectron Spectroscopy}

The methodology developed in Maheu et al. was applied to the oxysulfides powders. ${ }^{43}$ They were ultrasonically dispersed in heptane $(4 \mathrm{~g} / \mathrm{L})$ and several drops were deposited on a conducting ITO substrate $\left(\mathrm{R}_{\mathrm{S}}=30-60 \Omega / \mathrm{sq}\right.$, purchased from Merck). Solvent was removed in the ultra-high vacuum chamber of the apparatus during $48 \mathrm{~h}$. UPS analyses were conducted in an integrated ultrahigh vacuum system, connected to an A Axis Ultra DLD spectrometer (Kratos Analytical). UPS spectra were obtained with the first resonance line of a He lamp $(h v=21.2 \mathrm{eV})$. To separate the secondary edges of sample and analyzer, a negative potential about $9.1 \mathrm{eV}$ was applied to the sample. This bias was optimized adjusting the work function of a clean Ag foil. The cut-off energy is determined using the first derivative of the UP spectrum and spectra are aligned at the same cut-off, as argued in the supplementary information. At low binding energy, the contribution of the secondary electrons is strong, background subtraction is therefore needed. The background developed by $\mathrm{Li}$ et al. is used and $I_{\text {signal }}$ is plotted $\left(I_{\text {signal }}=I_{\text {exp }}-I_{\text {background }}\right){ }^{54}$ Spectra were normalized to compare significant variations of the density of states. We determined the valence band maximum $\left(\mathrm{E}_{\mathrm{VB}}\right)$ with a two times derivation of the spectra. The inflexion point is the $\mathrm{E}_{\mathrm{VB}}$. 
The intrinsic resolution of the apparatus is $0.2 \mathrm{eV}$, the error on the $\mathrm{E}_{\mathrm{VB}}$ is therefore: $\Delta \mathrm{E}_{\mathrm{VB}}=\left|\Delta_{\mathrm{UPS}}+\varepsilon\right|$ with $\varepsilon$ the error made with the graphical method $(\varepsilon \approx 0.2 \mathrm{eV})$. Note that similar results were obtained using the intersection point between the zero-intensity constant background and a linear extrapolation of the valence band decay. However, as discussed in Maheu et al., ${ }^{43}$ the second derivative method evidence the first electrons that are photogenerated from the top of the valence band.

\section{Authors contributions}

C.L. and A.M.N. performed the synthesis and characterization of the nanoparticles by XRD and TEM. E.G. and C.C. performed the photoluminescence measurements and their interpretation. L.P. performed the DFT modeling and interpretation. C.S., M.S. and P.L. contributed to the PDF measurements, validation and interpretation in relation with the proposed model. C.M., Ch.C. and L.C. performed the UPS measurements as well as their interpretation. C.L., A.G., C.S. and S.C. contributed to the project initiation and strategy, as well as on the crossed analysis of the information coming from the various characterizations, analytical techniques and modeling involved in this study. S.C. assumed the leadership of the overall project. All the authors contributed to the writing of the manuscript and to the validation of the results and interpretations. 


\section{Supporting information}

EDS of selected powders, picture of the nanoparticles powder, UV-vis reflectance spectra, complementary data treatment assuming an indirect bandgap in the Kubelka-Munk model, TEM of selected samples, powder XRD patterns, average size of the crystallites, FTIR spectra, models of the nanoparticles, details about the PDF and the DFT+U, complementary information from UPS, calculated band structure of $\mathrm{GdCeO}_{2} \mathrm{~S}$ slab. This material is available free of charge via the internet at http://pubs.acs.org.

\section{Competing interests}

The authors declare no competing interests.

\section{Acknowledgements}

This work was supported by French state funds managed by the ANR within the Investissements d'Avenir programme under reference ANR-11-IDEX-0004-02, and more specifically within the framework of the Cluster of Excellence MATISSE led by Sorbonne Université. We acknowledge funding for the PDF detector of our instrument from both the Institut de Matériaux de Paris Centre and the ANR project OxySUN (ANR-16-CE09-0005). The doctoral Program IPV of Sorbonne Universite is acknowledged for funding of the $\mathrm{PhD}$ thesis of AMN. Sorbonne Université, CNRS, and the Collège de France are acknowledged for financial support. This work was granted HPC resources under the GENCI allocation A0030907320.

\section{References}

(1) Pitha, J. J.; Smith, A. L.; Ward, R. The Preparation of Lanthanum Oxysulfide and Its Properties as a Base Material for Phosphors Stimulated by Infrared 1. J. Am. Chem. Soc. 1947, 69 (8), 1870-1871. 
(2) Zachariasen, W. H. Crystal Chemical Studies of the 5f-Series of Elements. VII. The Crystal Structure of Ce2O2S, La2O2S and Pu2O2S. Acta Crystallogr. 1949, 2 (1), 6062.

(3) Rossner, W.; Grabmaier, B. C. Phosphors for X-Ray Detectors in Computed Tomography. J. Lumin. 1991, 48-49 (1), 29-36.

(4) Michail, C. M.; Fountos, G. P.; Liaparinos, P. F.; Kalyvas, N. E.; Valais, I.; Kandarakis, I. S.; Panayiotakis, G. S. Light Emission Efficiency and Imaging Performance of Gd2O2S:Eu Powder Scintillator under x-Ray Radiography Conditions. Med. Phys. 2010, 37, 3694-3703.

(5) Auzel, F. Upconversion and Anti-Stokes Processes with f and d Ions in Solids. Chem. Rev. 2004, 104 (1), 139-174.

(6) Hyppänen, I.; Hölsä, J.; Kankare, J.; Lastusaari, M.; Pihlgren, L. Up-Conversion Luminescence Properties of Y2O2S:Yb3+,Er3+ Nanophosphors. Opt. Mater. (Amst). 2009, 31 (12), 1787-1790.

(7) Ajithkumar, G.; Yoo, B.; Goral, D. E.; Hornsby, P. J.; Lin, A.-L.; Ladiwala, U.; Dravid, V. P.; Sardar, D. K. Multimodal Bioimaging Using a Rare Earth Doped Gd2O2S:Yb/Er Phosphor with Upconversion Luminescence and Magnetic Resonance Properties. J. Mater. Chem. B 2013, 1 (11), 1561.

(8) Li, J.-G.; Wang, X.; Liu, W.; Zhu, Q.; Li, X.; Sun, X. (La0.97RE0.01Yb0.02)2O2S Nanophosphors Converted from Layered Hydroxyl Sulfate and Investigation of Upconversion Photoluminescence (RE=Ho, Er). Nanoscale Res. Lett. 2017, 12 (1), 508.

(9) Ajithkumar, G.; Yoo, B.; Goral, D. E.; Hornsby, P. J.; Lin, A.-L.; Ladiwala, U.; Dravid, V. P.; Sardar, D. K. Multimodal Bioimaging Using a Rare Earth Doped Gd2O2S:Yb/Er Phosphor with Upconversion Luminescence and Magnetic Resonance 
Properties. J. Mater. Chem. B 2013, 1 (11), 1561.

(10) Rosticher, C.; Viana, B.; Fortin, M.-A.; Lagueux, J.; Faucher, L.; Chanéac, C. Gadolinium Oxysulfide Nanoprobes with Both Persistent Luminescent and Magnetic Properties for Multimodal Imaging. RSC Adv. 2016, 6 (60), 55472-55478.

(11) Lei, L.; Zhang, S.; Xia, H.; Tian, Y.; Zhang, J.; Xu, S. Controlled Synthesis of Lanthanide-Doped Gd2O2S Nanocrystals with Novel Excitation-Dependent Multicolor Emissions. Nanoscale 2017, 9 (17), 5718-5724.

(12) Ding, Y.; Gu, J.; Ke, J.; Zhang, Y. W.; Yan, C. H. Sodium Doping Controlled Synthesis of Monodisperse Lanthanide Oxysulfide Ultrathin Nanoplates Guided by Density Functional Calculations. Angew. Chemie - Int. Ed. 2011, 50, 12330-12334.

(13) Sourisseau, C.; Cavagnat, R.; Mauricot, R.; Boucher, F.; Evain, M. Structure and Bondings in Cerium Oxysulfide Compounds I - Electronic, Infrared and Resonance Raman Spectra of Ce2.0O2.5S. J. Raman Spectrosc. 1997, 28 (12), 965-971.

(14) Sourisseau, C.; Fouassier, M.; Mauricot, R.; Boucher, F.; Evain, M. Structure and Bonding in Cerium Oxysulfide Compounds. II-Comparative Lattice Dynamics Calculations on Ce2O2S and Ce2.0O2.5S. J. Raman Spectrosc. 1997, 28 (12), 973978.

(15) Dugué, J.; Carré, D.; Guittard, M. Etude Structurale Des Oxysulfures de Cérium(III) et Cérium(IV). I. Structure Cristalline de l'Oxysulfure de Cérium Ce4O4S3. Acta Crystallogr. 1978, B34, 3564-3568.

(16) Dugué, J.; Carré, D.; Guittard, M. Etude Structurale Des Oxysulfures de Cérium(III) et Cérium(IV). II. Structure Cristalline de l'Oxysulfure de Cérium Ce6O6S4. Acta Crystallogr. 1979, B35, 1550-1554.

(17) Flahaut, J.; Guittard, M.; Patrie, M. Les Oxysulfures Me2O2S Des Éléments Du Groupe Des Terres Rares. Bull. Soc. Chim. Fr. 1958, 7, 990-994. 
(18) Quezel, G.; Ballestracci, R.; Rossat-Mignod, J. Proprietes Magnetiques Des Oxysulfures de Terres Rares. J. Phys. Chem. Solids 1970, 31 (4), 669-684.

(19) Larquet, C.; Nguyen, A.-M.; Ávila-Gutiérrez, M.; Tinat, L.; Lassalle-Kaiser, B.; Gallet, J.-J.; Bournel, F.; Gauzzi, A.; Sanchez, C.; Carenco, S. Synthesis of Ce2O2S and Gd2(1-y)Ce2yO2S Nanoparticles and Reactivity from in Situ X-Ray Absorption Spectroscopy and X-Ray Photoelectron Spectroscopy. Inorg. Chem. 2017, 56 (22), $14227-14236$.

(20) Mikami, M.; Nakamura, S. Electronic Structure of Rare-Earth Sesquioxides and Oxysulfides. J. Alloys Compd. 2006, 408-412, 687-692.

(21) Larquet, C.; Hourlier, D.; Nguyen, A.-M.; Torres-Pardo, A.; Gauzzi, A.; Sanchez, C.; Carenco, S. Thermal Stability of Oleate-Stabilized Gd 2 O 2 S Nanoplates in Inert and Oxidizing Atmospheres. ChemNanoMat 2019, 5, 539-546.

(22) Kubelka, P.; Munk, F. Ein Beitrag Zur Optik Der Farbanstriche. Zeitschrift für Tech. Phys. 1931, 12, 593-601.

(23) Tauc, J.; Grigorovici, R.; Vancu, A. Optical Properties and Electronic Structure of Amorphous Germanium. Phys. status solidi 1966, 15 (2), 627-637.

(24) Mikami, M.; Oshiyama, A. First-Principles Band-Structure Calculation of Yttrium Oxysulfide. Phys. Rev. B 1998, 57 (15), 8939-8944.

(25) Som, S.; Choubey, A.; Sharma, S. K. Spectral and Trapping Parameters of Eu 3+ in Gd 2 O 2 S Nanophosphor. J. Exp. Nanosci. 2015, 10 (5), 350-370.

(26) Bagheri, A.; Rezaee Ebrahim Saraee, K.; Shakur, H. R.; Zamani Zeinali, H. Synthesis and Characterization of Physical Properties of Gd2O2S:Pr3+ Semi-Nanoflower Phosphor. Appl. Phys. A Mater. Sci. Process. 2016, 122 (5), 1-8.

(27) Jeon, N. J.; Noh, J. H.; Yang, W. S.; Kim, Y. C.; Ryu, S.; Seo, J.; Seok, S. Il. Compositional Engineering of Perovskite Materials for High-Performance Solar Cells. 
Nature 2015, 517 (7535), 476-480.

(28) Ye, H.-Y.; Liao, W.-Q.; Hu, C.-L.; Zhang, Y.; You, Y.-M.; Mao, J.-G.; Li, P.-F.; Xiong, R.-G. Bandgap Engineering of Lead-Halide Perovskite-Type Ferroelectrics. Adv. Mater. 2016, 28 (13), 2579-2586.

(29) Zhou, R.; Wan, L.; Niu, H.; Yang, L.; Mao, X.; Zhang, Q.; Miao, S.; Xu, J.; Cao, G. Tailoring Band Structure of Ternary CdS x Se 1-x Quantum Dots for Highly Efficient Sensitized Solar Cells. Sol. Energy Mater. Sol. Cells 2016, 155, 20-29.

(30) Malerba, C.; Biccari, F.; Azanza Ricardo, C. L.; Valentini, M.; Chierchia, R.; Müller, M.; Santoni, A.; Esposito, E.; Mangiapane, P.; Scardi, P.; et al. CZTS Stoichiometry Effects on the Band Gap Energy. J. Alloys Compd. 2014, 582, 528-534.

(31) Tinoco, T.; Rincón, C.; Quintero, M.; Pérez, G. S. Phase Diagram and Optical Energy Gaps for CuInyGa1-ySe2 Alloys. Phys. Status Solidi 1991, 124 (2), 427-434.

(32) Farvid, S. S.; Wang, T.; Radovanovic, P. V. Colloidal Gallium Indium Oxide Nanocrystals: A Multifunctional Light-Emitting Phosphor Broadly Tunable by Alloy Composition. J. Am. Chem. Soc. 2011, 133 (17), 6711-6719.

(33) Ishikawa, A.; Takata, T.; Matsumura, T.; Kondo, J. N.; Hara, M.; Kobayashi, H.; Domen, K. Oxysulfides Sm2Ti2S2O5 as Stable Photocatalysts for Water Oxidation and Reduction under Visible-Light Irradiation. J. Am. Chem. Soc. 2002, 124 (8), 13547.

(34) Strehlow, W. H.; Cook, E. L. Compilation of Energy Band Gaps in Elemental and Binary Compound Semiconductors and Insulators. J. Phys. Chem. Ref. Data 1973, 2 (1), 163-200.

(35) Li, Q.; Meng, H.; Zhou, P.; Zheng, Y.; Wang, J.; Yu, J.; Gong, J. Zn 1- XCdxS Solid Solutions with Controlled Bandgap and Enhanced Visible-Light Photocatalytic H2Production Activity. ACS Catal. 2013, 3 (5), 882-889. 
(36) Zachariasen, W. H. Crystal Chemical Studies of the $5 \mathrm{f}$-Series of Elements. X. Sulfides and Oxysulfides. Acta Crystallogr. 1949, 2 (5), 291-296.

(37) Ding, Y.; Gu, J.; Ke, J.; Zhang, Y.-W.; Yan, C.-H. Sodium Doping Controlled Synthesis of Monodisperse Lanthanide Oxysulfide Ultrathin Nanoplates Guided by Density Functional Calculations. Angew. Chemie Int. Ed. 2011, 50 (51), 12330-12334.

(38) Zhang, T.; Gu, J.; Ding, Y.; Zhang, Y.-W.; Yan, C.-H. Experimental and Theoretical Studies on the Controlled Synthesis of Alkali-Metal-Doped Rare-Earth Oxysulfide Nanocrystals. Chempluschem 2013, 78 (6), 515-521.

(39) Shannon, R. D. Revised Effective Ionic Radii and Systematic Studies of Interatomic Distances in Halides and Chalcogenides. Acta Crystallogr. Sect. A 1976, 32 (5), 751767.

(40) Xu, J.; Tanabe, S.; Sontakke, A. D.; Ueda, J. Near-Infrared Multi-Wavelengths Long Persistent Luminescence of Nd 3+ Ion through Persistent Energy Transfer in Ce 3+, Cr 3+ Co-Doped Y 3 Al 2 Ga 3 O 12 for the First and Second Bio-Imaging Windows. Appl. Phys. Lett. 2015, 107 (8), 081903.

(41) Fu, J.; Parker, J. M.; Brown, R. M.; Flower, P. S. Compositional Dependence of Scintillation Yield of Glasses with High Gd2O3 Concentrations. In Journal of NonCrystalline Solids; 2003; Vol. 326-327, pp 335-338.

(42) Wang, Q.; Yang, B.; Zhang, Y.; Xia, H.; Zhao, T.; Jiang, H. High Light Yield Ce3+Doped Dense Scintillating Glasses. J. Alloys Compd. 2013, 581, 801-804.

(43) Maheu, C.; Cardenas, L.; Puzenat, E.; Afanasiev, P.; Geantet, C. UPS and UV Spectroscopies Combined to Position Energy Levels of TiO 2 Anatase and Rutile Nanopowders. Phys. Chem. Chem. Phys. 2018, No. type I, 25629-25637.

(44) Juhás, P.; Davis, T.; Farrow, C. L.; Billinge, S. J. L. PDFgetX3 : A Rapid and Highly Automatable Program for Processing Powder Diffraction Data into Total Scattering 
Pair Distribution Functions. J. Appl. Crystallogr. 2013, 46 (2), 560-566.

(45) Farrow, C. L.; Juhas, P.; Liu, J. W.; Bryndin, D.; Božin, E. S.; Bloch, J.; Proffen, T.; Billinge, S. J. L. PDFfit2 and PDFgui: Computer Programs for Studying Nanostructure in Crystals. J. Phys. Condens. Matter 2007, 19 (33), 335219.

(46) Farrow, C. L.; Billinge, S. J. L. Relationship between the Atomic Pair Distribution Function and Small-Angle Scattering: Implications for Modeling of Nanoparticles. Acta Crystallogr. Sect. A Found. Crystallogr. 2009, 65 (3), 232-239.

(47) Gilbert, B. Finite Size Effects on the Real-Space Pair Distribution Function of Nanoparticles. J. Appl. Crystallogr. 2008, 41 (3), 554-562.

(48) Anisimov, V. I.; Zaanen, J.; Andersen, O. K. Band Theory and Mott Insulators: Hubbard U Instead of Stoner I. Phys. Rev. B 1991, 44 (3), 943-954.

(49) Cococcioni, M.; de Gironcoli, S. Linear Response Approach to the Calculation of the Effective Interaction Parameters in the LDA+U Method. Phys. Rev. B 2005, 71 (3), 035105.

(50) Giannozzi, P.; Baroni, S.; Bonini, N.; Calandra, M.; Car, R.; Cavazzoni, C.; Ceresoli, D.; Chiarotti, G. L.; Cococcioni, M.; Dabo, I.; et al. QUANTUM ESPRESSO: A Modular and Open-Source Software Project for Quantum Simulations of Materials. J. Phys. Condens. Matter 2009, 21 (39), 395502.

(51) Giannozzi, P.; Andreussi, O.; Brumme, T.; Bunau, O.; Buongiorno Nardelli, M.; Calandra, M.; Car, R.; Cavazzoni, C.; Ceresoli, D.; Cococcioni, M.; et al. Advanced Capabilities for Materials Modelling with Quantum ESPRESSO. J. Phys. Condens. Matter 2017, 29 (46), 465901.

(52) Perdew, J. P.; Burke, K.; Ernzerhof, M. Generalized Gradient Approximation Made Simple [Phys. Rev. Lett. 77, 3865 (1996)]. Phys. Rev. Lett. 1997, 78 (7), 1396-1396.

(53) Dal Corso, A. Pseudopotentials Periodic Table: From H to Pu. Comput. Mater. Sci. 
2014, 95, 337-350.

(54) Li, X.; Zhang, Z.; Henrich, V. E. Inelastic Electron Background Function for Ultraviolet Photoelectron Spectra. J. Electron Spectros. Relat. Phenomena 1993, 63 (3), 253-265. 
Table of Content Entry

(Gd,Ce) ${ }_{2} \mathrm{O}_{2} \mathrm{~S}$ Nanoparticles
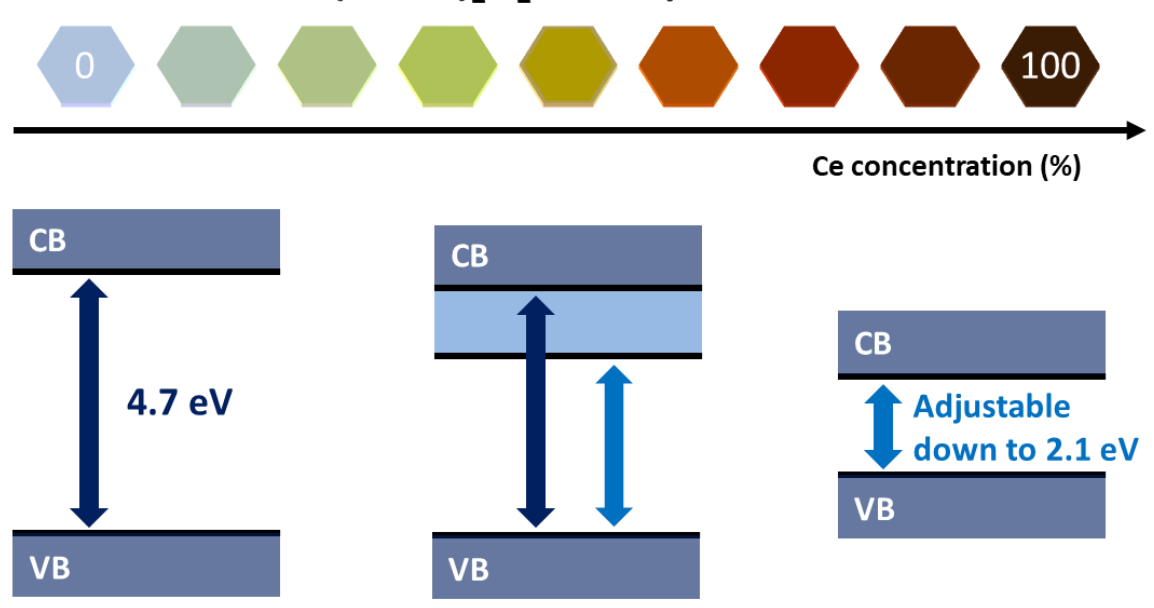

Pure

$\mathrm{Gd}_{2} \mathrm{O}_{2} \mathrm{~S}$

Doping regime $\mathrm{Ce}<5 \%$ Ce $>5 \%$ 